\title{
Complex Interplay between Oxidative Stress and Inflammatory signaling in Development of Neurodegenerative Diseases and Cancer
}

Loganathan Chandramani Priya Dharshini

PSG College of Arts and Science

Kunnathur Murugesan Sakthivel

PSG College of Arts and Science

Chinnadurai Kathirvelan

Tamil Nadu Veterinary and Animal Sciences University

Rasmi R R ( $\nabla$ rashmiffrajan@gmail.com )

PSG College of Arts and Science https://orcid.org/0000-0002-8180-278X

\section{Research Article}

Keywords: Oxidative Stress, Inflammation, Cancer, Transcription factors, neurodegenerative diseases

Posted Date: November 22nd, 2021

DOI: https://doi.org/10.21203/rs.3.rs-1018574/v1

License: (c) (i) This work is licensed under a Creative Commons Attribution 4.0 International License. Read Full License 


\section{Abstract \\ Introduction}

Oxidative stress (OS) and inflammation are closely related with cancer progression and neurodegenerative diseases. Excess ROS generated either oxidize biomolecules or triggers the signaling cascade thereby activating inflammation. The activation of inflammation causes immune cells to secrete cytokines and chemokines which recruits various immune cells to the site of infection or oxidative stress. This interrelation between oxidative stress and inflammation in cancer and neurodegenerative diseases is discussed in the article.

\section{Methods}

The role of oxidative stress and inflammation in cancer progression and neurodegenerative disease related literature were collected to obtain data. A narrative review was constructed after obtaining all the relevant information to provide a detailed note on it.

\section{Results}

In cancer, OS and inflammation aids in various oncogenic metabolic events including proliferation, differentiation, angiogenesis, migration, invasion, metabolic changes and evading programmed cell death. The disproportion between reactive oxygen species (ROS) and antioxidants in the body is termed as OS which damages the macromolecules (nucleic acids, lipids and proteins). It leads to dysfunction in biological signaling cascade. Prolonged oxidative stress triggers inflammation by stimulating transcription factors (NF-KB, p53, HIF-1a, PPAR- $\gamma$, Nrf2, AP-1) which altered expression of various other genes and proteins such as growth factors, tumor suppressor genes, oncogenes, pro-inflammatory cytokines etc., triggering cancer cells survival. In neurodegenerative diseases, both OS and inflammation activates astrocytes and microglia, which in turn altered energy metabolism, proteostasis and redox signaling in brain by activating various protein kinases.

\section{Conclusion}

The present review article delineates the complex interplay between OS and inflammation in some cancers (Colorectal, breast and lung cancer) and neurodegenerative diseases (Alzheimer's and Parkinson's disease).

\section{Introduction}

The interplay between oxidation and reduction is invariably pivotal for cellular signalling processes like proliferation, apoptosis, inflammation and immune responses [1]. The maintenance of redox metabolism 
and its equilibrium relies on the interaction of oxygen and nitrogen species with biomolecules. An alteration in the redox homeostasis is elucidative in the prognosis of various disease manifestations [2]. Oxidative metabolism as a result of aerobic respiration provokes the production of several compounds that are essential for molecular events namely gene expression, activation of enzymes, signal transduction, etc. However, cellular stress may increase the toxic levels of these compounds. The internal and external sources of oxidative stress are the detoxifying enzymes, radiation and chemical compounds respectively [3].

Reactive species are broadly classified into reactive oxygen species (ROS), reactive nitrogen species (RNS), reactive chloride species (RCS) and reactive sulfur species (RSS). Among these reactive species, ROS production is found to be more predominant in the cells to have potential impact on the rate of mutagenesis $[4,5]$. ROS include hydrogen peroxide $\left(\mathrm{H}_{2} \mathrm{O}_{2}\right)$, superoxide anion $\left(\mathrm{O}_{2}{ }^{-}\right)$, hydroxyl radical $\left(\mathrm{OH}^{-}\right)$, ozone $\left(\mathrm{O}_{3}\right)$ and singlet oxygen $\left({ }^{1} \mathrm{O}_{2}\right)[6]$. All these molecules were regarded deleterious for nucleic acids, lipids and proteins in the beginning. It was then studied that they play complex role in activating different physiological signaling cascades. These molecules are utilized in different metabolic pathways of mitochondria, endoplasmic reticulum and peroxisomes Mitochondria is the major reservoir of ROS where $2 \%$ of oxygen is estimated to form its superoxide. Peroxisomes host a number of free radical scavenging mechanisms via $\beta$-oxidation of fatty acids and catalase mediated hydrogen peroxide decomposition. In endoplasmic reticulum, generation of ROS takes place as a result of protein oxidation [7].

Increase in OS and aerobic respiration are two main attributes of cancer [8]. There is a constant pressure to sustain the balance between ROS and oxidative-stress responses. They demand unlimited energy for their deviant proliferation [9]. They are greatly linked with different types of cancer progression. For instance, small cell lung cancer (SCLC), non-small cell lung cancer (NSCLC), hepatocellular carcinoma etc. $[10,11]$. Many of the oncogenic cellular pathways and genes are evidenced to be combined with oxidative stress responses and epigenetic regulations [12]. For example, the signaling pathways of extracellular signal-regulated kinase (ERK), mitogen-activated protein kinase (MAPK) and JUN N-terminal kinase (JNK) that support tumor growth and survival are triggered by the oxygen species [13]. ROS and reactive nitrogen intermediates (RNI) mediate genetic damages causing inflammatory bowel disease (IBD), closely related with colorectal cancer development [14]. Malignancies of breast cancer are delineated by indicative levels of estrogen, being a major one for ROS generation. It initiates proteins intricated in proliferation and anti-apoptotic pathways vulnerable to redox signaling.

Hypoxic conditions engage adaptive responses in both physiological and pathological conditions via diverse cellular pathways that involves hypoxia-inducible factors, and endoplasmic reticulum stress responses [15]. Studies on brain pathology suggested an inverse interconnection between hypoxia and OS on the prospects of cancer and neurodegenerative diseases, for instance, sensitivity of nonmalignant glial cells and glioblastoma cancer cells to low oxygen [16]. ROS production has a direct control over the mechanism Epithelial-mesenchymal transition (EMT), that further enables tumor progression by allowing the cancer cells to colonize remote locations [17]. 


\section{Free Radicals- A Bridge Between Inflammation And Cancer}

Cancer risks higher when inflammation persists longer than usual. The free radical intermediates derived from nitrogen (RNI) and oxygen (ROI) inducts inflammatory cells to the damaged sites of tissues which ends up with cancer progression [18]. Mitochondria, cytochrome P450, peroxisomes and apoplast are the sole production centers of $\mathrm{ROI}$ and RNI that stimulates signals for intracellular transduction pathways, cell cycle and metabolism in favorable conditions [19]. Under unfavorable conditions, oxidative stress as well as nitrosative stress implicates the extracellular pathways related to metabolic stress. It reacts with biomolecules in the body to alternate the intra and intercellular equlibrium eventually ruling to cell death [20]. Activation of protein-kinase in non-phagocytic and phagocytic cells stimulates ROI and RNI production by proinflammatory cytokines and chemokines which aids the growth and proliferation in neoplastic cells simultaneously with the production of autocrine growth factor in tumor. Interleukins-6 (IL6), a multifunctional cytokine, levels up during the exposure to an inflammatory stimulus. In BALB/c mice in-vivo, prostaglandin ( $\mathrm{PGE}_{2}$ ) secretion from cyclooxygenase-2 (COX-2) elevated the level of IL-6 enhancing the growth of pristane-induced plasma cell tumors and also pristane elicited macrophages invitro [21]. Prostaglandin derived from the oxidation of arachidonic acid and certain other cytokines raises the level of ROI and RNI production that adds up to the amplification of cancer (Figure 1). It is stated that a toxic radical from nitrogen species namely peroxynitrate too stimulates the prostaglandin synthesis [22, 23]. At lower concentrations, the lipid oxidizes to form aldehydes and lipid peroxides acts as a signal transductor of ROI promoting expression of genes and proliferation of cells. While at higher concentrations, these lipid peroxides easily interact with biomolecules to generate a wide range of inter and intramolecular toxic covalent adducts that leads to increased oxidative stress [24].

\section{Mitochondria Integrate Ros Signaling And Cancer}

Mitochondria, a double-membraned organelle composed of matrix, outer and inner mitochondrial membrane (OMM \& IMM) with a middle intermembrane space region (IMS). OMM is the first barrier providing permeability of $\mathrm{Ca}^{2+}$ through high expression of voltage-dependent anion-selective channel proteins (VDACs) thereby creating pores in OMM to mediate the flux of ions, nucleotides and other metabolites [25]. A tight diffusion barrier called IMM, is specialized for the transportation of larger molecules which was allowed by a translocase namely translocases of the inner membrane (TIM) smaller molecules (carbon dioxide, water, oxygen) whereas, the movement of [26]. IMS involves in regulating mitochondrial respiration, transport of protein, lipid equilibrium and exchange of ions whereas matrix involves in diverse metabolic pathways as it contains a circular double-stranded DNA without histones namely mitochondrial DNA (mtDNA) [27].

mtDNA is known for its effective DNA repair mechanism and encodes 13 components for mitochondrial electron transport chain (mtETC) [28], which is composed of 4 complexes. Among those, NADH-CoQ reductase (Complex I) and cytochrome $\mathrm{C}$ reductase (complex III) are the major area for the superoxide $\left(\mathrm{O}_{2} \cdot{ }^{-}\right)$generation [29], which is a byproduct of oxidative phosphorylation (OXPHOS) bioenergetic 
metabolism. Superoxide dismutase converts it to $\mathrm{H}_{2} \mathrm{O}_{2}$ [30]. It leads to lose in mtDNA integrity, reduction in mtDNA copy number and acquires mutations which contribute for various diseases [31]. In addition, the modulation of mtROS production is due to the alterations in $\mathrm{Ca}^{2+}$ dynamics and transfer of lipids from endoplasmic reticulum to mitochondria [29]. mtROS together with ATP, cardiolipin, mitochondrial $\mathrm{Ca}^{2+}$ are transported to extracellular milieu or cytosol to stimulate the mito-inflammation through enhancing the levels of pro-inflammatory cytokines [32,33]. It promotes oxidative damage to various organelles and triggers the production of nuclear factor- kappa B (NF-kB), hypoxia-inducible factor 1 (HIF1) and activator protein-1 (AP-1) that provokes pro-inflammatory cytokines initiation namely Interleukin-6 (IL-6) and Interleukin-8 (IL-8) [34, 35]. The alteration in OXPHOS activity increases the mtROS due to the oxidative damage in mtDNA discharged from matrix interceding impaired mitophagy. These mtROS and mtDNA are identified by the pattern recognition receptors (PPRs) in the cytosol. They interact with other receptors to form the inflammasome complex in the cytosol, which then gets activated and induces cancer $[36,37]$.

In cancer, during the initiation and promotion stage, mtROS stimulate oxidation in mtDNA and causes damage. It increases mutation and structural changes in mtDNA with certain effects on expression and signalling in genes [38]. All these favours the apoptotic evasiveness in the advancement stage of cancer. It aids not only in the genomic instability but also influences the inflammatory cytokines of tumour cells and activates several transcription factors that modifies the energy of cancer cells [37]. In 1930s, Otto Warburg was the first to state that cancer is caused by mitochondrial dysfunction. Cancer cells adopt aerobic glycolysis to produce energy instead of OXPHOS in mitochondria which is called as Warburg switch [39]. A study stated that tumour progression is inhibited by preventing the lactate conversion from pyruvate by lactate dehydrogenase [40]. By stimulating the metabolism in mitochondria by OXPHOS, cancer cells proliferation is arrested [41]. In colorectal and lung cancers, a malignant potential increase in expression levels of glucose transporter (GLUT) proteins has been evidenced. All these data showed that the cancer cells accumulate more glucose for its metabolism [42]. All these findings state that cancer cells undergo Warburg effect that affects cellular events and increase in mtROS production. The proinflammatory cytokines increase the ROS production in mitochondria which enhances cancer progression (Figure 2).

\section{Inflammation And Oxidative Stress In Pathogenesis Of Diseases}

Inflammation contributes to carcinogenesis through various mechanisms such as instability in genome, changes in epigenetic events and consecutive irrelevant gene expression, increased differentiation of initiated cells, apoptotic resistance, aggressive tumour neovascularization, invasion in tumour-associated basement membrane, angiogenesis and metastasis. ROS, an effector molecule participates in host defence or acts as chemo-attractants volunteering leukocytes to wounded site, thereby prompting inflammatory reaction in tissue injured area. There are various cancer and diseases that are caused by oxidative stress followed by inflammation. 


\subsection{Colorectal cancer}

Colorectal cancer (CRC) is a perplexing multistage disease that has numerous mutations in oncogene as well as tumor suppressor genes such as $\mathrm{p} 53$, adenomatous polyposis coli (APC) and K-ras mutations [43]. was found widely in western countries with the highest mortality rates of $70-80 \%$ that occurs intermittently while the rest $20-30 \%$ of the cases develop through inherited factors. These uncommon CRC cases leads to obesity, physical inactivity, changes in environmental as well as lifestyle factors of the individual etc $[44,45]$. The increase in DNA oxidation and metabolic rate in CRC is mainly due to the rapid division of epithelial cells where CRC originates and lines the bowel [46]. In daughter cells, these DNA damages cannot be impaired and leads to mutation that could also result in cell cycle arrest, transcription activation, genomic instability closely linked with the initiation of carcinogenesis in colon [47]. Though, there is no history in the advancement of CRC after Inflammatory bowel disease (IBD), there is a major factor that recent inflammation and cancer prototype are being in the epidemiological studies along with its high frequency rate in IBD patients [48]. However, recent evidences stated that the ROS generation has a considerable role in cancer development [49]. The chronic inflammation in the intestine may leads to colon carcinogenesis in both type of IBD patients with Crohn's disease (CD) and ulcerative colitis (UC) [50] (Figure 3).

UC, a chronic inflammation is represented with large number of inflammatory cell infiltrations such as neutrophils, lymphocytes, plasma cells etc. These infiltrated cells are largely to generate higher levels of ROS, thereby stimulating OS and various protein degrading enzymes. These ROS and proteolytic enzymes cause severe damages to cells, which in turn inflate inflammatory damage, which subsequently enters into intestinal mucosal necrosis and ulceration, thereby, leading it to colon [51-53].

JAK/STAT protein acts as diagnostic as well as prognostic marker that has a vital play in the development and prolonged survival of CRC that is profoundly seen during lymph node metastasis and tumor infiltration depth [54]. The oxidative modifications of Cys253 residue, dimerizes and translocate STAT3 to nucleus by signalling activation [55]. There are various other passages involved in CRC such as MAPK, Wnt/ $\beta$-catenin and Notch signalling, PI3K/AKT. MAPK induces phosphorylation and activation of downstream genes including Ras through S-glutathionylation on Cys118 residue that generates higher ROS levels leading to CRC [56]. Wnt/ $\beta$-catenin and Notch signalling are modulated by NOX as they are redox-sensitive and are involved in proliferation, migration and differentiation of CRC [57]. PI3K/AKT was intimately linked to CRC where it has a contact between redox balanced oncogenic signalling and metabolic modification with CRC progression. An NADPH generating enzyme called methylenetetrahydrofolate dehydrogenase (MTNFD2) was upregulated by c-Myc through KRAS downstream effectors facilitating CRC growth and metastasis that includes PI3K/AKT and ERK pathways [58]. There are two types of receptor molecules that are involved in colon carcinoma progression namely positive and negative regulators. Positive regulators include proinflammatory cytokines like IL-1, IL-6, TNF- $\alpha$ and proinflammatory CC- chemokines. Negative regulators such as IL-10, TIR8 (also called single immunoglobulin IL-1R molecule, SIGIRR), TGF- $\beta$, cyclooxygenase-2 (COX-2) and others like innate 
immune cells and signalling molecules like toll-like receptors 4 (TLR4), MyD88 and important transcription factor named NF-kB [48].

In rat colonocytes, the lower crypt cells are prone to be very sensitive to hydrogen peroxide that causes severe damage than the differentiated surface cells. These cells are proliferating which are the putative target cells of colon carcinogenesis [47]. In human with colorectal cancer, it was observed that the patients had high RS levels and malondialdehyde (MDA), a product obtained from lipid peroxidation and decline in the sodium dismutase (SOD) and glutathione (GSH) levels [59]. MDA that acts as a marker for OS enhance the CRC aggression and advancement [60].

\subsection{Breast cancer}

Breast cancer (BC) is one of the most common cause of mortality in women. It is diagnosed by dysregulation in various molecular pathways and the sensitivity differences in the treatment aids in the survival of the inmates $[44,61]$. Chronic inflammation promotes various cellular related changes that initiates ROS production and enhances cell proliferation [62]. OS has a considerable play in breast cancer associated with dysfunctional adiposity and produces higher levels of ROS through various metabolic ways in obese and type 2 diabetes inmates [63,64]. Chronic inflammation is a type of cytokine-activated oxidative stress that initiates carcinogenesis in breast by producing instability in genome which takes it into malignant transformation where high frequency of DNA damage is linked with metastatic cancer cells increasing the growth and tumorigenic potential [65-67].

Gain in weight and obesity are of significant factor in post-menopausal women to predict the estrogendependent breast cancer (EDBC) [68]. Adipokines secreted from adipose tissue along with inflammatory cytokines and polypeptides are involved in EDBC initiation [69]. In overweight and obese women, concentration of leptin, TNF- $a$ and IL- 6 correlates with body mass index (BMI) and directly promotes carcinogenesis and all these are found in estrogen receptor (ER+) patients [70] (Figure 4).

Recent insights provide evidences that various pro-inflammatory cytokine (COX-2, IL1-b, IL-8, TNF-a) expression are convoluted in pathogenesis of $\mathrm{BC}$ [71]. These pro-inflammatory cytokine does not directly promote carcinogenesis through obesity related factors either it activates by insulin resistance or by the modification of aromatase activity in adipose tissue [72, 73]. Also, breast cancer development is associated with higher COX-2 levels and ROS production with increased levels of estrogen [74]. It has been stated that IL-8 simulated secretion aids in both invasion and angiogenesis enhancing tumor growth by causing disturbance to immune system [75]. II-6, an inflammatory cytokine is involved directly in the stimulation of NF-KB/STAT3 and induces insulin resistance $[76,77]$. This insulin resistance will downregulate the insulin-like growth factor (IGF) binding proteins that enhances the IGF-1 bioavailability and initiates tumor development in breast [78]. Additionally, necrosis, inflammation and immune response in tumor cells are related with TNF- $a$ [79]. Frequent cases of worsenning BC, higher expression of TNF- $a$ and IL1-b activates epithelial to mesenchymal transition and stimulates movement and adhesion [80]. ROS derived from IL1-b increases malignancy in breast cancer patients by improving cell proliferation and differentiation [81]. 
Because of weight gain, insulin resistance, IGF-1, inflammatory and metabolic changes, induces oxidative stress which damages nucleic acids, proteins, lipids, in turn activates Akt/PI3K/mTOR signalling which acts as a major pathway in promoting tumour growth, progression and modulating the receptor function of estrogen which is strictly associated with lipid, glucose metabolism for energy and regulation of autophagy [82-86]. The endocrine resistance mechanism is found in ER and PI3K/Akt/mTOR signalling and in ER+ MCF-7 cells, tamoxifen resistance is closely related with OS that increases JNK and c-Jun phosphorylation along with enhanced AP-1 activity. Both these resistance blockade stimulates anti-tumor activity in breast cancer models $[87,88]$.

Doxorubicin is an anthracycline used in BC treatment generates ROS by disrupting replication mechanism of DNA by binding to topoisomerase II leading to DNA damage [89]. Another drug called Paclitaxel stabilizes microtubules by modifying cell division causing cell mortality [90]. Both these drugs cause oxidative stress and $50 \%$ cytotoxic chemotherapy treatment develop resistance to breast cancer [91]. In $\mathrm{BC}$ patients, status of oxidative stress is reported by putative markers derived from lipid peroxidation process namely malondialdehyde, 8-F2-isoprostanes and 4-hydroxinoenal [92].

\subsection{Lung cancer}

Lung cancer (LC) is the top most killer cancer that is highly invasive, found both in men and women in United States of America (US) that causes higher mortality per year than the other next four highest deadliest cancer such as colon, breast, pancreas and prostate cancer death [93] according to International Agency for Research on Cancer. There are numerous types of lung cancers include adenocarcinoma, squamous cell carcinoma, SCLC and NSCLC [94].

Researches witnessed that tobacco inhaling contributes as an important risk factor where active smoking is dangerous while passive smoking causes some extend to LC (Doll and Hill, 1950). Smoking, an important factor causes pulmonary inflammation that activates macrophages, decreases neutrophils clearance and initiates oxidative stress $[95,96]$. Along with smoking, there are various factors contributes to $L C$ such as ambient air pollution especially particulate matter (PM), coal and waste burning indoor air pollutants from non-ventilated kitchens, carcinogenic metals like $\mathrm{Cd}, \mathrm{Ni}, \mathrm{As}, \mathrm{Cr}$, ionizing radiation like $\mathrm{a}$, $\mathrm{Y}^{-}$ rays. Other carcinogenic factors include industrial toxic exposures such as iron and steel founding, rubber production, diesel fumes and silica dusts and organic chemicals with carcinogenic potential such as dioxins and polychlorinated compounds that attributes for lung cancer when the individual had long term exposure to these carcinogens [97]. All the above-mentioned extrinsic factors after long term exposure initially promotes oxidative stress followed by chronic inflammation. Inmates with lung cancer, there is a huge level of OS and inflammation in bronchial epithelium [98].

LC development involves various stages namely initiation, promotion and development [99]. In the first stage of initiation, inflammation causes direct damage to DNA causing mutation or erratic effect stimulated by variety of enzymes generating ROS leading to DNA and protein damage. Secondly, during promotion of LC, oxidative stress initiates the formation of focal lesions causing invasive cancers. Progression is the last stage where malignant cells are formed from neoplastic clones. c-Jun and c-Fos re 
oncogenes induced by ROS generated from inflammatory cells. Also, higher expression of c-Jun was witnessed in LC individuals [100] (Figure 5).

A variety of TF such as NF-KB, AP-1 (activator protein), p53 (tumor suppressor gene), HIF-1a, PPAR-y (peroxisome proliferator-activated receptor gamma), Wbt/ $\beta$-catenin, Nrf2 (nuclear factor erythroid 2related factor 2) are triggered by OS having a considerable role in initiation and promotion of LC [101, 102]. All these TF overexpresses various other genes namely genes of growth factor, inflammatory cytokines, cell-cycle regulatory molecules and anti-inflammatory molecules. Thereby, OS stimulated inflammatory pathways transforms normal cell to tumor cell, enhancing its durability, proliferation, differentiation, angiogenesis, chemoresistance and radioresistance. Therefore, OS, chronic inflammation and LC are closely related [103-105].

\subsection{Alzheimer's disease}

Alzheimer's disease (AD) is a complex neurodegenerative disease. It is often linked with aged-dementia and extensive neuronal loss in hippocampus, amygdala, enterorhinal and neocortex regions which is separated into familial AD (FAD) and sporadic forms $[106,107]$. Various genes involved with the accretion of fibrillar proteins. Example: extra-cellular amyloid $\beta(A \beta)$ plaques and neurofibrillary tangles (NFTs) have been identified and it leads to death after 3-9 years of diagnosis. These genes are a direct causative forms during the early-onset of the disease. Example: Amyloid precursor protein (APP) gene (chromosome 21) and presenilin (PS) genes 1 and 2 (chromosomes 14 and 1). Mutations identified on the APP, PS1 or PS2 genes result in amyloidogenesis means, the increased production of $\beta$-amyloid peptide [108]. The symptoms are dysfunction ranging from slow to progressive cognitive skills, decline in memory, language disturbances and physical disabilities [109].

Besides the pathological expression in $A D$, diseased brain evidences are reported caused as substantial damage due to brain atrophy, chronic inflammation, oxidative stress, extracellular and intracellular deposition of $A \beta$ and NFTs respectively leading to neurodegeneration [110]. When the natural antioxidant, glutathione level becomes low and the neural membranes contain a higher ratio of polyunsaturated fatty acids, the neurons become extremely vulnerable to free radicals and the brain metabolism will require a considerable amount of oxygen [111]. Studies from both dead and live patients, along with transgenic mouse models, shows insights of the bridge between ROS, inflammation and AD. Several surrogate markers of ROS-mediated injury are found to be greatly enlarged in the brain and cerebrospinal fluid of AD patients. A few, such markers mentioned are 1) LPO - malondialdehyde, 4-hydroxynonenal, F2isoprostanes 2) protein oxidation - protein carbonyls, nitrotyrosine 3) DNA oxidation - 8-hydroxy-2'deoxyguanosine, respectively [112]. Insulin regulates appetite, glucose level and homeostasis of lipid in hypothalamus of the brain. So, when insulin signaling and transport of glucose is disrupted, it predominantly causes AD $[113,114]$ (Figure 6).

TREM2 gene associated with sporadic AD codes for cell surface protein. The knockdown of this gene brings cognitive impairment followed by the high levels of pro-inflammatory cytokines such as IL-6 and TNF- $a$, and decline in anti-inflammatory cytokines namely IL-10 in senescence-accelerated mouse prone- 
8 (SAMP8) brain model [115]. An adaptor protein named DAP12 associates with TREM2 that serves as an important factor for survival, proliferation, chemotaxis and phagocytosis of microglia in mice [116]. Microglia- predominant immune cells, involved in the homeostasis of central nervous system (CNS) during stress, disease, trauma and pathology and also attributed to the remodeling of neuronal circuits [117-119]. Either these immune cells exert neuroprotection by the phagocytic mechanism on $A \beta$, subsequently the loss in function exacerbate amyloidosis followed by inflammation, synaptic loss and further leads to neuronal loss $[120,121]$, or the inability of the microglial to clear $A \beta$ fails, it activates proinflammatory passage leading to inflammation and OS in $\operatorname{AD}[122,123]$.

ROS generated in the neurons interacts with any of the biomolecule causing oxidative stress to proteins. It breaks down the metabolism process, proteostasis and redox motion in the brain by stimulating various stress-related protein kinases namely JNK, mitogen activated protein kinase (p38) and ERK1/2 or brings about oxidative modifications in redox-sensitive transcription factors [124, 125]. ROS generated from two sources serves as a major donor to the AD pathophysiology includes transition metals like Fe and $\mathrm{Cu}$ acts as a ligand to $A \beta$ and also mitochondrial dysfunction.

In addition, ROS from activated microglia induces inflammatory response in the brain of AD patients where NOX has a considerable play role in $\operatorname{AD}[126,127]$. The upregulation of microglial NOX2 is triggered from multiple sources like Aß42. Along with NOX2 derived ROS, proinflammatory cytokines, chemokines further activate microglia and causes neuronal damage through linking inflammation and oxidative damage in the pathogenesis of AD [128].

\subsection{Parkinson's disease}

Parkinson's disease (PD) is recognized by the cumulative neurodegeneration of pigmented nigrostriatal dopaminergic neurons (DA) and Lewy bodies formation, which are eosinophilic inclusions comprising intracytoplasmic aggregates of a-synuclein. The clinical manifestations of PD have both motor and nonmotor signs. The major motor indications of PD are akinesia (complication in starting voluntary actions), bradykinesia (leisure down of movements) and extrapyramidal rigidity (muscle groups become stiffer) [129].

The general factors behind neuronal degeneration are environmental toxins, genetic factors and oxidative stress. OS is linked with PD progression in highly oxidative conditions that generally prevail in DA. Mitochondrial dysfunction is also documented in PD. For instance, respiratory enzyme in complex-I was suppressed by the neurotoxin 1-methyl-4-phenyl-1,2,3,6-tetrahydropyridine (MPTP) causing PD. Moreover, tetrahydrobiopterin, an endogenous compound inhibits mitochondrial complexes I and IV, causing malfunction in the electron transport chain, oxidative stress and conclusively has PD symptoms [130]. In the pathogenesis of $\mathrm{PD}$, increasing recognition of neuroinflammation to have a possible role are witnessed. They are shown to be stimulated by the vulnerability to infectious particles with proinflammatory characteristics [131] (Figure 7). 
DA loss was witnessed due to oxidative stress that progresses to PD [132]. These unstable neurons oxidize to form quinone and $\mathrm{H}_{2} \mathrm{O}_{2}$ in the brain of PD patients simultaneously reacting with oxygen or iron forming hydroxyl radical $\left(\mathrm{OH}^{-}\right)$. Dopaminergic neurotoxicity is caused by the interaction of DA quinone synthesized from catechin epoxidation of dopamine and cysteine residues where DA is inactivated by the removal of sulfhydryl groups, interferes with dysfunction of mitochondria and protein functions is inhibited $[133,134]$. Sulfhydryl groups in the proteins react with DA metabolites and form adducts which damages the intracellular thiol group, aids with the advancement of PD [135]. Also, OS causes a disproportionate in the build-up of ROS bringing mitochondrial dysfunction [136]. Recent evidence suggested that rotenone (ROT) is another major risk factors in the PD pathophysiology [137].

Neuronal inflammation is mainly due to the microglia stimulation. Various studies stated that in PD patients with microglial overactivation, neuronal cell death was observed in substantia nigra [138, 139]. In addition, stimulated microglia are found in other regions of brain namely basal ganglia and pontine [140]. This microglia in activated form are composed of two different cells having opposite functions. The polarized microglia are of two extremes namely M1 pro-inflammatory (classically activated) and M2 antiinflammatory (alternately activated) phenotypes [141]. M1 is morphologically altered and discharges numerous inflammatory components (TNF-a, IT-1, IL-6 and nitric oxide (NO)) leading to DA neuronal loss in PD patients [142]. M2 synthesizes anti-inflammatory cytokines (IL-4, IL-13, IL-10, TGF) via phagocytic effects that reduces inflammation and repairs the inflammatory response thereby microglia-mediated neuroinflammation plays both as positive and negative response in PD progression $[143,144]$. Oxidative stress and neuroinflammation plays major role in PD through microglia-mediated neurotoxicity using two mechanisms. NOX activation induces the generation of huge extracellular ROS and also increases ROS intracellularly in microglia. This microglia-mediated OS stimulates pro-inflammatory genes generation [145]. 
Table 1

Oxidative stress and inflammation in certain disease and cancer and its mechanism

\begin{tabular}{lll}
$\begin{array}{l}\text { S. No } \\
\text { No }\end{array}$ & Diseases & Mechanism \\
\hline 1. & $\begin{array}{l}\text { Alzheimer's } \\
\text { disease }\end{array}$ & $\begin{array}{l}\text { T2DM is due to resistance in insulin level playing a considerable } \\
\text { part in Alzheimer's disease. Chronic inflammation and OS } \\
\text { combined with T2DM enhances the build-up of A protein and } \\
\text { tangles in neurons along with mitochondrial dysfunction leading to } \\
\text { the formation of } A D .\end{array}$
\end{tabular}

2. Parkinson's Exogenous and endogenous factors induce OS in the brain. While, disease neuroinflammation is due to the deposition of huge amount of proinflammatory factors through blood brain barrier. Recent studies reported that lipopolysaccharides induce chronic inflammation along with rotenone-induced ROS to stimulate the damage and create a progressive loss in dopamine neurons that leads to formation of Lewy bodies and a-synuclein accumulation causing PD.

Reference

3. $\begin{aligned} & \text { Prion } \\ & \text { disease }\end{aligned} \quad$ is transmissible neurodegenerative disease that is incurable
caused by misfolding of cellular protein (PrPsc). Higher oxidative stress level, initiates the normal prion protein (PrPc) conversion to infectios prion protein (PrPsc). Along with PrPsc, metal ions like $\mathrm{Cu}$ and Fe interacts in the progression of prion disease. PrPsc accumulation in neurons enhances inflammation causing loss of function in neurons and leads to neuronal death.

4. Colorectal cancer

One mechanism in the pathogenesis of colon cancer, ulcerative colitis. It is a chronic inflammation caused by variety of infiltrated cells which generate ROS stimulating oxidative stress. These stress damages nucleic acids, followed by inflammatory damage and subsequently causes necrosis and ulceration in intestine, leading to the formation of colon carcinogenesis.
5. Breast Various pro-inflammatory cytokines activate breast cancer by cancer activating insulin resistance and modifying aromatase activity in adipose tissue. In addition, cytokines IL-1 $\beta$ generates ROS and enhances cell proliferation and differentiation in breast cancer cells.

Chronic inflammation is stimulated by various external factors namely viruses, bacteria, smoke, pollution etc. This type of inflammation induces ROS and affects the hepatocytes, leading to the initiation and progression of LC.

6. $\quad$ Lung Overproduction of ROS enhances proinflammatory cytokines (IL-6, TNF-a) promoting proliferation in cancer cells. Also, cytokines enhance ROS generation thereby, forming a cyclic phenomenon. Additionally, JAK/STAT-3 pathway closely related with malignant transformation of urothelial cells that progresses bladder cancer.

8. Gastric In gastric cancer, inflammation and OS are linked with $H$. pylori that cancer damages DNA. This DNA damage induced progression of gastric cancer from normal infection stage.

\section{Discussion}


Oxidative stress is a disproportionate between antioxidants and ROS present in the body. It results in hazardous conditions including cancer, atherosclerosis, neurological problems, perfusion, diabetes and many more [154]. Generally, when ROS levels are increased it damages DNA followed by a signalling cascade stimulated by other TFs and inflammatory cytokines eventually leading to chronic inflammation [155]. Inflammation is a response triggered by the body to various pathogens, alcohol exposure, toxic chemicals etc. It is not a disease rather it is a biological/cellular process which is closely linked with pathophysiology of various other diseases including insulin resistance, T2DM, cardiovascular diseases, obesity combined inflammatory diseases [156].

Cancer is an abnormal growth of cells that intracellularly maintains deleterious level of ROS to enhance oxidative stress and creates a tumor microenvironment with the help of inflammatory cells [157]. Cancer cells adapt to high levels of ROS by modifying sulphur metabolism, NADPH production and antioxidant activity [158].

Neurodegenerative disorders are gradual loss of particular liable group of neurons due to metabolic or toxic diseases. It is classified into three types namely early clinical features (eg: motor neuron disease, dementia), anatomic neurodegeneration (eg: extrapyramidal disorders, frontotemporal degenerations) or principal molecular abnormality [159]. Recent evidence witnessed that genetic alterations, cellular changes and circuit dysregulation in brain leads to cognitive hallmarks of neurodegenerative diseases [160].

Accumulation of oxidants are witnessed in the oncogenic conversion of normal cells which is an important requirement for the cancer cells to survive along with the inflammatory mediator's aids in proliferation, differentiation, angiogenesis, metastasis and invasiveness. Inflammation in the starting stage of a disease activates the immune cells and recruits the cell to tissue injured site and eliminate the foreign substances. But prolonged inflammation activates various immune cells along with proinflammatory and anti-inflmmatory cytokines, chemokines, prostaglandins, cyclooxygenase and ROS as well as nitric oxide causes OS leading to the enhancement and progression of diseased state [161, 162]. Therefore, prolonged inflammation along with oxidative stress alters normal cell metabolism and signalling pathways that enhances cancer and other pathological neurodegenerative disease. Both inflammation and oxidative stress are complex events which concludes with the cancer as well as neurodegenerative disease progression and the cellular mechanism still remains subtle.

\section{Conclusion}

This review mainly focusses on the role of oxidative stress and inflammation and their complex interplay in cancer and neurodegenerative disease. Numerous pathways have a considerable play in linking oxidative stress and inflammation in various cancers and neurodegenerative diseases. Either oxidative stress appears first or inflammation occurs. Both the oxidative stress and inflammation occurs one after other, which take part in pathogenesis of disease. 


\section{Declarations}

\section{Data Availability}

Not Applicable.

\section{Author contributions}

All authors contributed to the study conception and design. The first draft of the manuscript was written by LCP. KMS, CK and RRR provided critical revisions of the work. All authors read and approved the final manuscript.

\section{Acknowledgement}

The authors are thankful to Dr.D.Brindha, Principal, PSG College of Arts \& Science, Coimbatore for providing valuable support.

\section{Compliance with ethical standards}

\section{Funding}

The authors would like to acknowledge Department of Health Research for providing financial assistance to Dr.R.R.Rasmi in the form of Young Scientist (Funding No:12014/11/2018- HR/E-office:3151264).

\section{Conflicts of interest}

The authors declare they have no conflicts of interest.

\section{Ethical Approval}

This article does not contain any studies with human participants or animals performed by any of the authors.

\section{References}

1. R.A. Cairns, I.S. Harris, T.W. Mak, Regulation of cancer cell metabolism, Nat. Rev. Cancer. 11 (2011) 85-95.

2. W.S. Wu, The signaling mechanism of ROS in tumor progression, Cancer Metastasis Rev. 25 (4) (2006) 695-705.

3. V. Sosa, T. Moline, R. Somoza, R. Paciucci, H. Kondah, M.E. Lleonart, Oxidative stress and cancer: An overview, Aging Res. Rev. (2012).

4. S. Reuter, C.S. Gupta, M.M. Chaturvedi, B.B. Agarwal, Oxidative stress, Inflammation and Cancer: How they are linked? Free Radic. Biol. Med. 49 (11) (2010) 1603-1616. 
5. T. Hussain, B. Tan, Y. Yin, F. Blachier, M.C.B. Tossou, N. Rahu, Oxidative stress and Inflammation: What polyphenols can do for us? Oxid. Med. Cell. Longevity. (2016) 7432797.

6. M. G. Simic, D.S. Bergtold, L.R.Karam, Generation of oxyradicals in biosystems, Mut. Res. 214 (1989) 3-12.

7. T. Finkel, Signal transduction by mitochondrial oxidants, J. Biol. Chem. 287 (2012) 4434-4440.

8. C. Gorrini, I.S. Harris, T.W. Mak, Modulation of oxidative stress as an anticancer strategy, Nat. Rev. Drug Dis. 12 (2013) 931-947.

9. D. Trachootham, J. Alexandre, P. Huang, Targeting cancer cells byROS-mediated mechanisms: a radical therapeutic approach? Nat. Rev. Drug Dis. 8 (2009) 579-591.

10. H. Esme, M. Cemek, M. Sezer, et al, High levels of oxidative stress in patients with advanced lung cancer, Respirology. 13 (1) (2008) 112-116.

11. Y. Sasaki, Does oxidative stress participate in the development of hepatocellular carcinoma? J. Gastroenterol. 41 (12) (2006) 1135-1148.

12. M.W. Lawless, K.J. Byrne, S.G. Gray, Targeting oxidative stress in cancer, Expert opinion on therapeutic targets. 14 (11) (2010) 1225-1245.

13. J.L. Martindale, N.J. Holbrook, Cellular response to oxidative stress: signaling for suicide and survival, J. Cell. Physiol. 192 (2002) 1-15.

14. T. Irrazabal, B.K. Thakur, M. Kang, Y. Malaise, C. Streutker, E.O.Y. Wong, J. Copeland, R. Gryfe, D.S. Guttman, W.W. Navarre, A. Martin, Limiting oxidative DNA damage reduces microbe-induced colitisassociated colorectal cancer, Nat. Commun. 11 (2020).

15. Y.L. Chua, E. Dufour, E.P. Dassa, P. Rustin, H.T. Jacobs, C.T. Taylor, T. Hagen, Stabilization of hypoxiainducible factor-1 a protein in hypoxia occurs independently of mitochondrial reactive oxygen species production, J. Biol. Chem. 285 (41) (2010) 31277-31284.

16. K. Krawczynski, J. Godlewski, A. Bronisz, Oxidative Stress-Part of the Solution or Part of the Problem in the Hypoxic Environment of a Brain Tumor, Antioxidants, 9 (8) (2020) 747.

17. E. Giannoni, M. Parri, P. Chiarugi, EMT and oxidative stress: a bidirectional interplay affecting tumor malignancy. Antioxid. Redox Signal. 16 (11) (2012) 1248-1263.

18. A. Federico, F. Morgillo, C. Tuccillo, F. Ciardiello, C. Loguercio, Loguercio C. Chronic inflammation and oxidative stress in human carcinogenesis, Int. J. Cancer, 121 (11) (2007) 2381-2386.

19. C. Nathan, Specificity of a third kind: reactive oxygen and nitrogen intermediates in cell signalling, J. Clin. Invest. 111 (2003) 769-778.

20. K.D. Kroncke, Nitrosative stress and transcription, Biol.Chem, 384 (1011) (2003) 1365-1377.

21. R. M. Hinson, J.A. Williams, E. Shacter, Elevated interleukin 6 is induced by prostaglandin E2 in a murine model of inflammation: possible role of cyclooxygenase, Proc. Nat. Acad. Sci. U. S. A. 93 (10) (1996) 4885-4890.

22. J.A. Baron, R.S. Sandler, Nonsteroidal anti-inflammatory Drugs and Cancer Prevention, Annu. Rev. Med. 51 (2000) 511-523. 
23. R.J. Moore, D.M. Owens, G. Stamp, C. Arnott, F. Burke, N. East, H. Handsworth, L. Turner, B. Rollins, M. Pasparakis, G. Kollias, F. Balkwill, Mice deficient tumor necrosis factor-a are resistant to skin carcinogenesis, Nat. Med. 5 (1999) 828-831.

24. K. Uchida, 4-Hydroxy-2-nonenal: a product and mediator of oxidative stress, Prog. Lipid Res. 42 (2003) 318-343.

25. C. Giorgi, S. Marchi, P. Pinto, The machineries, regulation and cellular functions of mitochondrial calcium, Nat. Rev. Mol. Cell Biol. 19 (11) (2018) 713-730.

26. W. Kuhlbrandt, Structure and function of mitochondrial membrane protein complexes, BMC Biol. 13 (2015) 89.

27. S. Patergnani, E. Bouhamida, S. Leo, P. Pinton, A. Rimessi, Mitochondrial oxidative stress and "MitoInflammation": Actors in the disease, Biomedicines. 9 (2021) 216.

28. P.A. Gammage, C. Frezza, Mitochondrial DNA: The overlooked oncogenome? BMC Biol. 17 (2019) 53.

29. A. Rimessi, M. Previati, F. Nigro, M.R. Wieckoeski, P. Pinton, Mitochondrial reactive oxygen species and inflammation: Molecular mechanisms, diseases and promising therapies, Int. J. Biochem. Cell Biol. 81 (2016) 281-293.

30. H. Nohl, L. Gille, K. Staniek, Intracellular generation of reactive oxygen species by mitochondria, Biochem. Pharamacol. 69 (2005) 719-723.

31. A. Hahn, S. Zuryn, Mitochondrial Genome (mtDNA) mutations that generate reactive oxygen species, Antioxidants 8 (2013) 392.

32. K. McArthur, L.W. Whitehead, J.M. Heddleston, L. Li, B.S. Padman, V. Oorschot, N.D. Geoghegan, S. Chappaz, S. Davidson, H. San Shin, R.M. Lane, M. Dramicanin, T. L. Saunders, C. Sugiana, R. Lessene, L.D. Osellame, T.L. Chew, G. Dewson, M. Lazarou, G. Ramm, G. Lessene, M.T. Ryan, K.L. Rogrers, M.F.V. Delft, B.T. Kile, BAK/BAX macropores facilitate mitochondrial herniation and mtDNA efflux during apoptosis. Science 359 (2018) 6378.

33. H. Kalkavan, D.R. Green, MOMP, cell suicide as a BCL-2 family business, Cell Death Differ. 25 (2018) 46-55.

34. K.D. Mansfield, R.D. Guzy, Y. Pan, R.M. Young, T.P. Cash, P.T. Schumacker, M.C. Simon, Mitochondrial dysfunction resulting from loss of cytochrome $\mathrm{C}$ impairs cellular sensing and hypoxic HIF-alpha activation. Cell Metabolism, 1 (2015) 393-399.

35. H. Ichimura, K. Parthasarathi, S. Quadri, A.C. Issekutz, J. Bhattacharya, Mechano-oxidative copuling by mitochondria induces pro-inflammatory responses in lung venular capillaries, J. Clin. Invest. 111 (2003) 691-699.

36. T. Kawai, S. Akira, TLA signaling, Cell Death Diff. 13 (2006) 816-825.

37. F. Weinberg, N. Ramnath, D. Nagrath, Reactive oxygen species in the Tumor micrpenvironment: An overview, Cancers 11 (2019) 1191.

38. Z. Dong, S. Shanmughapriya, D. Tomar, N. Siddiqui, S. Lynch, N. Nemani, S.L. Breves, X. Zhang, A. Tripathi, P. Palaniappan, M.F. Riitano, A.M. Worth, A. Seelam, E. Carvalho, R. Subbiah, F. Jana, J. 
Soboloff, Y. Peng, J.Y. Cheung, S.K. Joseph, J. Caplan, S. Rajan, P.B. Stathopulos, M. Madesh, Mitochonsrial $\mathrm{Ca}(2+)$ uniporter is a mitochondrial luminal redox sensor that augments MCU channel activity, Mol. Cell 65 (2017) 1014-1028.

39. N. Lee, D. Kim, Cancer Metabolism: Fueling more than just growth, Mol. Cell 39 (2016) 847-854.

40. V.R. Fantin, J. St-Pierre, P. Leder, Attentuation of LDH-A expression uncovers a link between glycolysis, mitochondrial physiology and tumor maintenance, Cancer Cell 9 (2006) 425-434.

41. T.J. Schulz, R. Thierbach, A. Voigt, G. Drewes, B. Mietzner, P. Steinberg, A.F. Pfeiffer, M. Ristow, Introduction of oxidative metabolism by mitochondrial frataxin inhibits cancer growth: Otto Warburg revisited, J. Biol. Chem. 281 (2006) 977-981.

42. M. Wu, A. Neilson, A.L. Swift, R. Moran, J. Tamagnine, A. Parslow, S. Armistead, K. Lemire, J. Orrell, J. Teich, S. Chomiz, D.A. Ferrick, Multiparameter metabolic analysis reveals a close link between attenuated mitochondrial bioenergetic function and enhanced glycolysis dependency in human tumor cells, Am. J. Physiol. Cell Physiol. 292 (2007) C125-C136.

43. S. Aretz, H. F. A. Vasen, and S. Olschwang, Clinical utility gene card for: familial adenomatous polyposis (FAP) and attenuated FAP (AFAP), Eur. J. Human Genet. 19 (7) (2011).

44. A. Jemal, F. Bray, M. M. Center, J. Ferlay, E. Ward, D. Forman, Global cancer statistics, Cancer J. Clin. 61 (2) (2011) 69-90.

45. J. Souglakos, Genetic alterations in sporadic and hereditary colorectal cancer: implementations for screening and followup, Digestive Dis. 25 (1) (20017) 9-19.

46. M. Foksinski, R. Rozalski, J. Guz, B. Ruszkowska, P. Sztukowska, M. Piwowaeski, A. Klungland, R. Olinski, Urinary excretion of DNA repair products correlates with metabolic rates as well as with maximum life spans of different mammalian species, Free Radic. Biol. Med. 37 (9) (2004) 14491454.

47. D. L. Oberreuther-Moschner, G. Rechkemmer, and B. L. PoolZobel, Basal colon crypt cells are more sensitive than surface cells toward hydrogen peroxide, a factor of oxidative stress, Toxicol. Lett. 159 (3) (2005) 212-218.

48. S. Danese, A. Mantovani, Inflammatory bowel disease ad intestinal cancer: a paradigm of the YinYang interplay between inflammation and cancer, Oncogene 29 (2013) 3313-3323.

49. M. Valko, D. Leibfritz, J. Moncol, M. T. D. Cronin, M. Mazur, and J. Telser, Free radicals and antioxidants in normal physiological functions and human disease, Int. J. Biochem. Cell Biol. 39 (1) (2007) 44-84.

50. S. Gyde, P. Prior, M.J. Dew, V. Saunders, J.A. Waterhouse, R.N. Allan, Mortality in ulcerative colitis, Gastroenterol. 83 (1982) 36-43.

51. M.A. Bitton, D.A. Peppercorn, D.A. Antonioli, J.L. Niles, S. Shah, A. Bousvaros, B. Ransil, G. Wild, A. Cohen, M.D. Edwardes, A.C. Stevens, Clinical, biological, and histologic parameters as predictors of relapse in ulcerative colitis, Gastroenterol. 120 (1) (2001) 13-20.

52. N. Oshitani, Y. Sawa, J. Hara, K. Adachi, S. Nakamura, T. Matsumoto, T. Arakawa, T. Kuroki, Functional and phenotypical activation of leucocytes in inflamed human colonic mucosa, J. 
Gastroenterol. 12 (12) (1997) 809-814.

53. Z. Wang, S. Li, Y. Cao, X. Tian, R. Zeng, D. Liao, D. Cao, Oxidative stress and carbonyl lesions in Ulcerative colitis and associated colorectal cancer, Oxid. Med. Cell. Longevity (2016) 9875298.

54. S. Tang, X. Yuan, J. Song, Y. Chen, X. Tan, Q. Li, Association analyses of the JAK/STAT signaling pathway with the progression and prognosis of colon cancer. Oncol. Lett. 17 (2019) 159-164.

55. L. Li, P.E. Shaw, A STAT3 dimer formed by inter-chain disulphide bridging during oxidative stress. Biochem. Biophys. Res. Commun. 322 (2004) 1005-1011.

56. A. Greenhough, H.J. Smart, A.E. Moore, H.R. Roberts, A.C. Williams, C. Paraskeva, A. Kaidi, The COX2/PGE2 pathway: Key roles in the hallmarks of cancer and adaptation to the tumour microenvironment. Carcinogenesis 30 92009) 377-386.

57. H. Liu, X. Liu, C. Zhang, H. Zhu, Q. Hu, Y. Bu, Y. Lei, Redox imbalance in the development of colorectal cancer, J. Canc. 8 (2017) 1586-1597.

58. H.Q. Ju, Y.X. Lu, D.L. Chen, Z.X. Zuo, Z.X. Liu, Q.N. Wu, H.Y. Mo, Z.X. Wang, D.S. Wang, H.Y. Pu, Z. Zeng, B. Li, D. Xie, P. Huang, M. Hung, P.J. Chiao, R. Xu, Modulation of redox homeostasis by inhibition of MTHFD2 in colorectal cancer: Mechanisms and therapeutic implications. J. Natl. Cancer Inst. 111 (2019) 584-596.

59. J.N. Myers, M.W. Schaffer, O.Y. Korolkova, A.D. Williams, P.R. Gangula, A.E. MKoma, Implications of the colonic deposition of free hemoglobin-a chain: A previously unknown tissue by-product in inflammatory bowel disease. Inflamm Bowel Dis. 20 (2014) 1530-1547.

60. T. Obtułowicz, A. Winczura, E. Speina, M. Swoboda, J. Janik, B. Janowska, J.M. Cieśla, P. Kowalczyk, A. Jawien, D. Gackowski, Aberrant repair of etheno-DNA adducts in leukocytes and colon tissue of colon cancer patients. Free Radic Biol Med.49 (2010) 1064-1071.

61. R. Rouzier, C. M. Perou, W.F. Symmans, N. Ibrahim, M. Cristofanilli, K. Anderson, K.R. Hess, J. Stec, M. Ayers, P. Wagner, P. Morandi, C. Fan, I. Rabiul, J.S. Ross, G.N. Hortobagyi, L. Pusztai, Breast cancer molecular subtypes respond differently to preoperative chemotherapy. Clin Cancer Res. 11 (16) (2005) 5678-5685.

62. L.M. Coussens, Z. Werb, Inflammation and cancer, Nature 420 (6917) (2002) 860-867.

63. A.B. Crujeiras, A. Diaz-Lagares, M.C. Carreira, M. Amil, F.F. Casanueva, Oxidative stress associated to dysfunctional adipose tissue: a potential link between obesity, type 2 diabetes mellitus and breast cancer, Free Radic. Res. 47 (2013) 243-256.

64. Q. Dai, Y.T. Gao, X.O. Shu, G. Yang, G. Milne, Q. Cai, W. Wen, N. Rothman, H. Cai, Y. Xiang, W. Chow, W. Zheng, Oxidative stress, obesity, and breast cancer risk: results from the Shanghai Women's Health Study, J Clin Oncol. 27 (2009) 2482-2488.

65. S.A. Hills, J.F. Diffley, DNA replication and oncogene-induced replicative stress, Curr Biol CB. 24 (10) (2014) R435-44.

66. I. Heirman, D. Ginneberge, R. Brigelius-Flohe, N. Hendrickx, P. Agostinis, P. Brouckaert, P. Rottiers, J. Grooten, Blocking tumor cell eicosanoid synthesis by GPx4 impedes tumor growth and malignancy, Free Radic. Biol. Med. 40 (2) (2006) 285-294. 
67. P.K. Mahalingaiah, K.P. Singh, Chronic oxidative stress increases growth and tumorigenic potential of MCF-7 breast cancer cells, PLoS One. 9 (1) (2014) e87371.

68. T. Key, P. Appleby, I. Barnes, G. Reeves, Endogenous sex hormones and breast cancer in postmenopausal women: reanalysis of nine prospective studies, J Natl Cancer Inst. 94 (2002) 60616.

69. L. Vona-davis, D.P. Rose, Adipokines as endocrine, paracrine, and autocrine factors in breast cancer risk and progression, Endocr Relat Cancer. 14 (2007) 189-206.

70. E.E. Kershaw, J.S. Flier, Adipose tissue as an endocrine organ, J Clin Endocrinol Metab. 89 (2004) 2548-2556.

71. V.S. Rao, C.E. Dyer, J.K. Jammel, P.J. Drew, J. Greenman, Potential prognostic and therapeutic roles for cytokines in breast cancer (Review), Oncol Rep. 15 (1) (2006) 179-185.

72. H. Ruan, H.F. Lodish, Insulin resistance in adipose tissue: Direct and indirect effects of tumor necrosis factor-a, Cytokine Growth Factor Rev. 14 (2003) 447-455.

73. A. Purohit, M.W. Ghilchik, L. Duncan, D.Y. Wang, A. Singh, M.M. Walker, M.J. Reed, Aromatase activity and interleukin-6 production by normal and malignant breast tissues, J Clin Endocrinol Metab. 80 (1995) 3052-3058.

74. S. Basu, R. Nachat-Kappes, F. Caldefie-Chezet, M.P. Vasson, Eicosanoids and adipokines in breast cancer: from molecular mechanisms to clinical considerations, Antioxid Redox Signal. 1 (3) (2013) 323-360.

75. C. Madeddu, G. Gramignano, C. Floris, G. Muren, G. Sollai, A. Maccio, Role of inflammation and oxidative stress in postmenopausal oestrogen-dependent breast cancer, J Cell Mol Med. 18 (12) (2014) 2519-2529.

76. S. Ghosh, K. Ashcraft, An IL-6 link between obesity and cancer, Front Biosci. 5 (2013) 461-478.

77. J.L. Sarvas, N. Khaper, S.J. Lees, The IL-6 paradox: context dependent interplay of SOCS3 and AMPK, J Diabetes Metab. (2013).

78. D. Sachdev, D. Yee, The IGF system and breast cancer, Endocr Relat Cancer. 8 (2001) 197-200.

79. M. Leppkes, M. Roulis, M.F. Neurath, G. Kollias, C. Becker, Pleiotropic functions of TNF-alpha in the regulation of the intestinal epithelial response to inflammation, Int Immunol. 26 (9) (2014) 509-515.

80. G. Sorio, M. Ofri-Shahak, I. Haas, N. Yaal-Hahoshen, L. Leider-Trejo, T. Leibovich-Rivkin, P. Weitzenfeld, T. Meshel, E. Shabtai, M. Gutman, A. Ben-Baruch, Inflammatory mediators in breast cancer: coordinated expression of TNFalpha \& IL-1 beta with CCL2 \& CCL5 and effects on epithelial-tomesenchymal transition, BMC Cancer. 11 (2011) 130.

81. A.R. Nourazarian, P. Kangari, A. Salmaninejad, Roles of oxidative stress in the development and progression of breast cancer, Asian Pac J Cancer Prev. 15 (12) (2014) 4745-4751.

82. P. Kangari, T. Zarnoosheh Farahany, A. Golchin, S. Ebadollahzadeh, A. Salmaninejad, S.A. Mahboob, A. Nourazarian, The lipid peroxidation in breast cancer patients, Gen Physiol Biophys. 29 (2010) 208210. 
83. S.D. Hursting, N.A. Berger, Energy balance, host-related factors, and cancer progression, J Clin Oncol. 28 (2010) 4058-4065.

84. A. Acharya, I. Das, D. Chandhok, T. Saha, Redox regulation in cancer: a double-edged sword with therapeutic potential, Oxid Med Cell Longev. 3 (2010) 23-34.

85. I. Vucenik, J.P. Stains, Obesity and cancer risk: evidence, mechanisms, and recommendations, Ann NY Acad Sci. 1271 (2012) 37-43.

86. T.W. Grunt, G.L. Mariani, Novel approaches for molecular targeted therapy of breast cancer: interfering with PI3K/AKT/mTOR signaling, Curr Cancer Drug Targets. 13 (2013) 188-204.

87. E. Karlson, G. Perez-Tenorio, R. Amin, J. Bostner, L. Skoog, T. Fornander, D.C. Sgroi, B. Nordenskjold, A. Hallbeck, O. Stal, The mTOR effectors 4EBP1 and S6K2 are frequently coexpressed, and associated with a poor prognosis and endocrine resistance in breast cancer: a retrospective study including patients from the randomised Stockholm tamoxifen trials, Breast Cancer Res. 15 (5) (2013) R96.

88. R. Schiff, P. Reddy, M. Ahotupa, E. Coronado-Heinsohn, M. Grim, S.G. Hilsenbeck, R. Lawrence, S. Deneke, R. Herrera, G.C. Chamness, S.A. Fuqua, P.H. Brown, C.K. Osborne, Oxidative stress and AP-1 activity in tamoxifen-resistant breast tumors in vivo, J Natl Cancer Inst. 92 (23) (2000) 1926-1934.

89. C. F. Thorn, C. Oshiro, S. Marsh, T. Hernandez-Boussard, H. McLeod, T.E. Klein, R.B. Altman, Doxorubicin pathways: pharmacodynamics and adverse effects, Pharmacogenet Genomics. 21 (7) (2011) 440-446.

90. R. Yusuf, Z. Duan, D. Lamendola, R. Penson, and M. Seiden, Paclitaxel resistance: molecular mechanisms and pharmacologic manipulation, Curr Cancer Drug Targets. 3 (1) (2003) 1-19.

91. C. Panis, V. J. Victorino, A. C. S. A. Herrera, A.L. Cecchini, A.N.C. Simao, L.Y. Tomita, R. Cecchini, Can breast tumors affect the oxidative status of the surrounding environment? A comparative analysis among cancerous breast, mammary adjacent tissue, and plasma, Oxid Med Cellular Longev. 2016 (2016) 6429812.

92. F.Manello, G.A.Tonti, S.Pagliarini, S.Benedetti, F.Canestrari, W.Zhu, W.Qin, E.R. Sauter, The 8-epimer of prostaglandin $\mathrm{F}$ (2 alpha), a marker of lipid peroxidation and oxidative stress, is decreased in the nipple aspirate fluid of women with breast cancer, Int J Cancer. 120 (9) (2007) 1971-1976.

93. J. Bishop, Cancer facts \& figures 2014. Atlanta: American Cancer Society. Harwood academic publications (2014).

94. International Agency for Research on Cancer (WHO). GLOBOCAN 2012: Estimated Cancer Incidence, Mortality and Prevalence Worldwide in 2012. Lung Cancer: Fact sheets, IARC (2012).

95. R. Doll, A.B. Hill, Smoking and carcinoma of the lung: Preliminary report, Br Med J. 2 (4682) (1950) 739-748.

96. T. Walser, X. Cui, J. Yanagawa, J.M. Lee, E. Heinrich, G. Lee, S. Sharma, S.M. Dubinett, Smoking and lung cancer: the role of inflammation. Proc Am Thorac Soc. 5 (8) (2008) 811-805.

97. R.W. Field, B.L. Withers, Occupational and environmental causes of lung cancer, Clin Chest Med. 33 (4) (2012) 681-703. 
98. E. Barreiro, C. Fermosell, M. Mateu-Jimenez, A. Sanchez-Font, L. Pijuan, J. Gea, V. Curull, Oxidative stress and inflammation in the normal airways and blood of patients with lung cancer and COPD, Free Radic. Biol. Med. 65 (2013) 859-871.

99. D. Hanahan, R.A. Weinberg, Hallmarks of cancer: The next generation, Cell. 144 (5) (2011) 646-674.

100. N. Azad, Y. Rojanasakul, V. Vallyathan, Inflammation and lung cancer: Roles of reactive oxygen/ nitrogen species. J Toxicol Envron Health: Critical Reviews B. 11 (1) (2008) 1-15.

101. I. Rahman, Oxidative stress, transcription factors and chromatin remodelling in lung inflammation. Biochem. Parmacol. 64 (5-7) (2002) 935-942.

102. I. Rahman, W. MacNee, Role of transcription factors in inflammatory lung diseases, Thorax. 55 (1998) 601-612.

103. S. Shalapour, M. Karin, Immunity, inflammation, and cancer: an eternal fight between good and evil, J Clin Invest. 125 (9) (2015) 3347-3355.

104. S. Reuter, S.C. Gupta, M.M. Chaturved, B.B. Aggrawal, Oxidative stress, inflammation, and cancer: How are they linked? Free RAdic. Biol. Med. 49 (11) (2010) 1603-1616.

105. K. Taniguchi, M. Karin, NF-kB, inflammation, immunity and cancer: coming of age, Nat Rev Immunol. 18 (2018) 309-324.

106. P. Johns, Dementia, in: Clinical Neuroscience. Elsevier (2014) 145-162.

107. S. Chakrabarti, M. Sinha, I. Thakurta, P. Banerjee, M. Chattopadhyay, Oxidative stress and amyloid beta toxicity in Alzheimer's disease: intervention in a complex relationship by antioxidants, Curre Med Chem. 20 (37) (2013) 4648-4664.

108. Y. Christen, Oxidative stress and Alzheimer disease, Am J Clin Nutr. 71 (2) (2000) 621S-629S.

109. D.M. Holtzman, J.C. Morris, A.M. Goate, Alzheimer's disease: the challenge of the second century. Sci. Transl. Med. 3 (2011) 77srl.

110. L. M. Ittner, J. Gotz, Amyloid-beta and tau-a toxic pas de " deux in Alzheimer's disease, Nat Rev Neurosci. 12 (2) (2011) 67-72.

111. L. Packer, L. Prilipko, Free radicals in the brain: aging, neurological and mental disorders, Springer Sci Business Media. (2012).

112. Y. Yao, C. Chinnici, H. Tang, J.Q. Trojanowski, V.M. Lee, D. Praticò, Brain inflammation and oxidative stress in a transgenic mouse model of Alzheimer-like brain amyloidosis, J Neuroinflam. 1 (1) (2004) $1-9$.

113. S. Dore, S. Kar, W. Rowe, R. Quirion, Distribution and levels of [125I] IGF-I, [125I] IGF-II and [125I] insulin receptor binding sites in the hippocampus of aged memory-unimpaired and -impaired rats, Neurosci. 80 (4) (1997) 1033-1040.

114. Z. Chen, C. Zhong, Decoding Alzheimer's disease from perturbed cerebral glucose metabolism: implications for diagnostic and therapeutic strategies, Progress in Neurobiology 108 (2013) 21-43.

115. H. Zheng, L. Jia, C.C. Liu, Z. Rong, L. Zhong, L. Yang, X.F. Chen, J.D. Fryer, X. Wang, Y.W. Zhang, H. Xu, G. Bu, TREM2 Promotes Microglial Survival by Activating Wnt/ $\beta$-Catenin Pathway, J. Neurosci. 37 
(2017) 1772-1784.

116. L. Zhong, Z.L. Zhang, X. Li, C. Liao, P. Mou, T. Wang, Z. Wang, Z. Wang, M. Wei, H. Xu, G. Bu, X.F. Chen, TREM2/DAP12 Complex Regulates Inflammatory Responses in Microglia via the JNK Signaling Pathway, Front. Aging Neurosci. 9 (2017) 204.

117. L. Tian, C.W. Hui, K. Bisht, Y. Tan, K. Sharma, S. Chen, X. Zhang, M.E. Tremblay, Microglia under psychosocial stressors along the aging trajectory: Consequences on neuronal circuits, behavior, and brain diseases. Prog. Neuropsychopharmacol. Biol. Psychiatry 79 (2017) 27-39.

118. R.M. Ransohoff, J. El Khoury, Microglia in Health and Disease. Cold Spring Harb. Perspect. Biol. 8 (2015) a020560.

119. T.L. Tay, J.C. Savage, C.W. Hui, K. Bisht, M.E. Tremblay, Microglia across the lifespan: from origin to function in brain development, plasticity and cognition, J. Physiol. 595 (2017) 1929-1945.

120. V.H. Perry, C. Holmes, Microglial priming in neurodegenerative disease, Nat. Rev. Neurol. 10 (2014) 217-224.

121. A. ElAli, S. Rivest, Microglia in Alzheimer's disease: A multifaceted relationship. Brain. Behav. Immun. 55 (2016) 138-150.

122. S. Piirainen, A. Youssef, C. Song, A.V. Kalueff, G.E. Landreth, T. Malm, L. Tian, Psychosocial stress on neuroinflammation and cognitive dysfunctions in Alzheimer's disease: the emerging role for microglia? Neurosci. Biobehav. Rev. 77 (2017) 148-164.

123. C.Y.D. Lee, G.E. Landreth, The role of microglia in amyloid clearance from the AD brain. J. Neural Transm. 117 (2010) 949-60.

124. D.A. Butterfield, F. Di Domenico, A.M. Swomley, E. Head, M. Perluigi, Redox proteomics analysis to decipher the neurobiology of Alzheimer-like neurodegeneration: overlaps in Down's syndrome and Alzheimer's disease brain, Biochemical J. 463 (2) (2014) 177-189.

125. B. Su, X. Wang, A. Nunomura, P.I. Moreira, H-gon Lee, G. Perry, M.A> Smith, X. Zhu, Oxidative stress signaling in Alzheimer's disease, Curr Alzheimer Res. 5 (6) (2008) 525-532.

126. U. Kaur, P. Banerjee, A. Bir, M. Sinha, A. Biswas, S. Chakrabarti, Reactive oxygen species, redox signaling and neuroinflammation in Alzheimer's disease: the NF-KB connection, Curr Topics Med Chem. 15 (5) (2015) 446-457.

127. C. Cheignon, M. Tomas, D. Bonnefont-Rousselot, P. Faller, C. Hureau, F. Collin, Oxidative stress and the amyloid beta peptide in Alzheimer's disease, Redox Biol. 14 (2018) 50-464.

128. U. Ganguly, U. Kaur, S.S. Chakrabarti, P. Sharma, B.K. Agrawal, L. Saso, S. Chakrabarti, Oxidative stress, Neuroinflammation, and NADPH Oxidase: Implications in the pathogenesis and treatment of Alzheimer's disease, Oxid Med Cellular Longev. 2021 (2021) 19.

129. R. Deumens, A. Blokland, J. Prickaerts, Modeling Parkinson's disease in rats: an evaluation of 6OHDA lesions of the nigrostriatal pathway, Exp Neuro. 175 (2) (2002) 303-317.

130. T.B. Sherer, R. Betarbet, J.T. Greenamyre, Environment, mitochondria, and Parkinson's disease, The Neuroscientist. 8 (3) (2002) 192-197. 
131. P.S. Whitton, Inflammation as a causative factor in the aetiology of Parkinson's disease, British $\mathrm{J}$ Pharmacol. 150 (8) (2007) 963-976.

132. F.N. Emamzadeh, A. Surguchov, Parkinson's disease: biomarkers, treatment, and risk factors, Front. Neurosci. 12 (2018) 612.

133. A.H. Gautam, G.D. Zeevalk, Characterization of reduced and oxidized dopamine and 3,4dihydrophenylacetic acid, on brain mitochondrial electron transport chain activities, Biochim Biophys Acta. 1807 (7) (2011) 819-828.

134. W. Ma, H.T. Liu, Y.T. Long, Monitoring dopamine quinone-induced dopaminergic neurotoxicity using dopamine functionalized quantum dots, ACS Appl Materials Interfaces. 7 (26) (2015) 14352-14358.

135. A. Farzam, K. Chohan, M. Strmiskova, S.J. Hewitt, D.S. Park, J.P. Pezacki, D. Ozceik, A functionalized hydroxydopamine quinone links thiol modification to neuronal cell death. Redox Biol. 28 (2020) 101377.

136. F. Vatansever, W.C.M.A. De Melo, P. Avci, D. Vecchio, M. Sadasivam, A. Gupta, R. Chandran, M. Karimi, N.A. Parizotto, R. Yin, G.P. Tegos, M.R. Hamblin, Antimicrobial strategies centered around reactive oxygen species - bactericidal antibiotics, photodynamic therapy, and beyond, FEMS Microbiology Reviews. 37 (6) (2013) 955-989.

137. C.M. Tanner, F. Kamel, G.W. Ross, J.A. Hoppin, S.M. Goldman, M. Korell, C. Marras, G.S. Bhudhikanok, M. Kasten, A.R. Chade, K. Comyns, M.B. Richards, C. Meng, B. Priestley, H.H. Fernandez, F. Cambi, D.M. Umbach, A. Blair, D.P. Sandler, J.W. Langston, Rotenone, paraquat, and Parkinson's disease, Environmental Health Perspectives. 119 (6) (2011) 866-872.

138. A.J. Filiano, S.P. Gadani, J. Kipnis, Interactions of innate and adaptive immunity in brain development and function, Brain Research. 1617 (2015) 18-27.

139. C. Lecours, M. Bordeleau, L. Cantin, M. Parent, T.D. Paolo, M.E. Tremblay, Microglial implication in Parkinson's disease: loss of beneficial physiological roles or gain of inflammatory functions? Front Cell Neurosci. 12 (2018) 282.

140. S.R. Subramaniam, H.J. Federoff, Targeting microglial activation states as a therapeutic avenue in Parkinson's disease, Front Aging Neurosci. 9 (2017) 176.

141. F.Y. McWhorter, C.T. Davis, W.F. Liu, Physical and mechanical regulation of macrophage phenotype and function, Cell Mol Life Sci. 72 (7) (2015) 1303-1316.

142. S.H. Ho, Microglia in Parkinson's disease, Adv Exp Med Biol. 1175 (2019) 335-353.

143. J.D. Cherry, J.A. Olschowka, M. O'Banion, Neuroinflammation and M2 microglia: the good, the bad, and the inflamed, J Neuroinflam. 11 (1) (2014) 98.

144. C. Angeloni, C. Prata, F. Vieceli Dalla Sega, R. Piperno, S. Hrelia, Traumatic brain injury and NADPH oxidase: a deep relationship, Oxid Med Cell Longev, 2015 (370312) (2015) 10.

145. G. Verdile, K.N. Keane, V.F. Cruzat, S. Medic, M. Sabale, J. Rowles, N. Wijesekara, R.N. Martins, P.E. Fraser, P. Newsholme, Inflammation and Oxidative Stress: The molecular connectivity between insulin resistance, obesity and Alzheimer's disease, Mediators of Inflammation. 105828 (2015) 1-17. 
146. J. He, G. Zhu, G. Wang, F. Zhang, Oxidative stress and Neuroinflammation Potentiate each other to promote progression of dopamine neurodegeneration, Oxid Med Cell Longev. (2020) 6137521.

147. K.N. Prasad, S.C. Bondy, Oxidative and Inflammatory events in prion diseases: Can they Be therapeutic targets? Curr Aging Sci. 11 (4) (2018) 216-225.

148. U. Weiss, Inflammation, Nature. 454 (7203) (2008) 427.

149. K.A. Head, J.S. Jurenka, Inflammatory bowel disease Part 1: ulcerative colitis-pathophysiology and conventional and alternative treatment options, Alternat Med Rev. 8 (3) (2003) 247-283.

150. M.J. Reed, L. Topping, N.G. Coldham, A. Purohit, M.W. Ghilchik, V.H. James, Control of aromatase activity in breast cancer cells: the role of cytokines and growth factors. J Steroid Biochem Mol Biol. 44 (4-6) (1993) 589-596.

151. M. Gomes, A.L. Teixeira, A. Coelho, A. Araujo, R. Medeiros, Inflammation and Lung Cancer: Oxidative stress, ROS, and DNA damage, Reactive Oxygen Species in Biology and Human Health (2016).

152. P. Wigner, R. Grebowski, M. Bijak, J. Saluk-Bijak, J. Szemraj, The interplay between oxidative stress, inflammation and angiogenesis in bladder cancer development, Int J Mol Sci. 22 (2021) 4483.

153. D.M. Hardbower, T. Sablet, R. Chaturvedi, K.T. Wilson, Chronic inflammation and oxidative stress: The smoking gun for Helicobacter pylori -induced gastric cancer? Gut Microbes 4 (6) (2013) 475-481.

154. J.C. Preiser, Oxidative stress. J Parent Enter Nutr. 36 (2) 147-154.

155. L.C.P. Dharshini, S. Vishnupriya, K.M. Sakthivel, R.R. Rasmi, Oxidative stress responsive transcription factors in cellular signalling transduction mechanisms. Cellular Signalling. 72 (2020) (109670) 1-9.

156. T. Hussain, B. Tan, Y. Yin, F. Blachier, M.C.B. Tossou, N. Rahu, Oxidative stress and Inflammation: What polyphenols can do for us? Oxid Med Cellular Longev. 2016 (2016) 7432797.

157. F. Mantovani, L. Collavin, G. Del Sal, Mutant p53 as a guardian of the cancer cell, Cell Death Differ. 26 (2019) 199-212.

158. J.D. Hayes, A.T. Dinkova-Kostova, K.D. Tew, Oxidative stress in Cancer, Cancer Cell. 38 (2) (2020) 167197.

159. B.N. Dugger, D.W. Dickson, Pathology of Neurodegenerative Diseases, Cold Spring Harbor Perspectives in Biology. 9 (7) (2017) a028035.

160. M. Heemels, Neurodegenerative diseases, Nature 539 (2016) 179.

161. G.Y. Liou, P. Storz, Reactive oxygen species in cancer. Free Radic Res. 44 (2010) 479-496.

162. R.L. Blaylock, Cancer microenvironment, inflammation and cancer stem cells: a hypothesis for a paradigm change and new targets in cancer control, Surg Neurol Int. 6 (2015) 92.

\section{Figures}




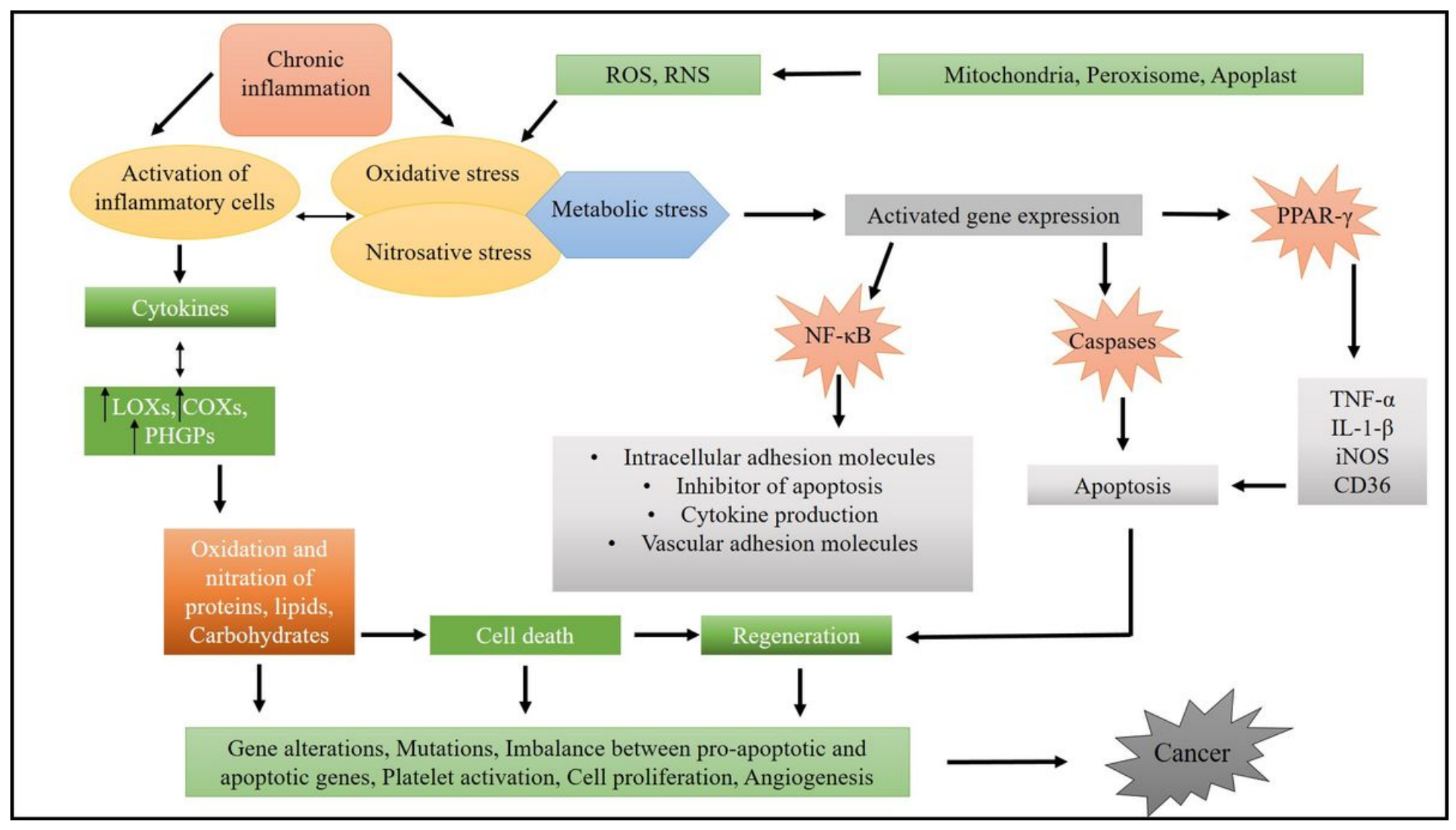

\section{Figure 1}

The main steps involved in inflammation that leads to cancer via free-radical stress. ROS/RNS causes oxidative stress and nitrosative stress which is also activated by chronic inflammation that induces inflammatory cells and activates gene expression via various pathways such as NF-KB, Caspases, PPAR$Y$, IL-1 $\beta$, TNF-a, iNOS and CD36. In addition, the cytokines released from inflammatory cells induces oxidation and nitration of lipids, proteins and carbohydrates. All these transcription factors along with cytokines stimulate apoptosis thereby creating an imbalance between pro-apoptotic and apoptotic gene environment that simultaneously leading to regeneration, cell death and eventually causing cancer through gene alterations, mutations, proliferation, angiogenesis etc. 


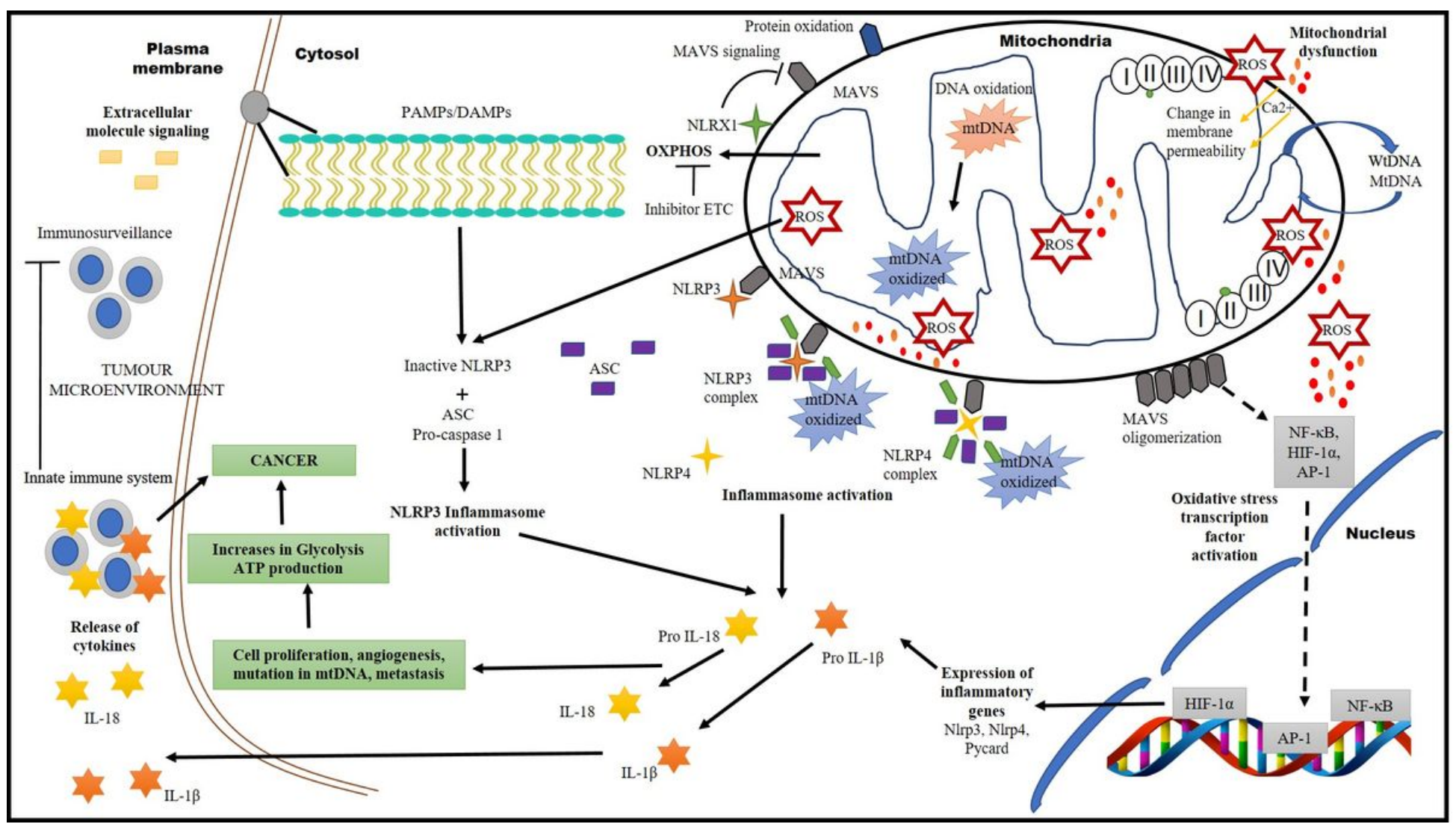

Figure 2

mtROS leads to Mito-inflammation that induces cancer. In mitochondria, excess releases of ROS oxidize mitochondrial DNA and also excess calcium in mitochondria changes membrane permeability thereby causing mutation in mtDNA and brings about dysfunction in mitochondria. Inflammasome activation is of three mechanisms: first, mitochondrial anti-viral signaling protein (MAVS) oligomerizes via oxidative stress activating various TFs (NF-KB, HIF-1a, AP-1). All these TF expresses many other inflammatory genes (NIrp3, Nlrp4, pycard). Secondly, NLR family pyrin domain containing 3 (NLRP3) receptors after interacting with oxidized mtDNA forms a complex with apoptosis-associated speck-like protein containing a CARD (ASC) and activates inflammasome. Thirdly, the inactive NLRP3 from plasma membrane on interaction with ROS and ASC Pro-caspase 1 also form NLRP3 inflammasome complex. All the three mechanisms, simultaneously activates IL-18 and II-1 $\beta$ that enhances proliferation, angiogenesis, metastasis and DNA mutation that increases glycolysis and ATP production causing cancer. In tumor microenvironment, immunosurveillance takes place by innate immune system which is inhibited due to the proliferation of cancer cells. 


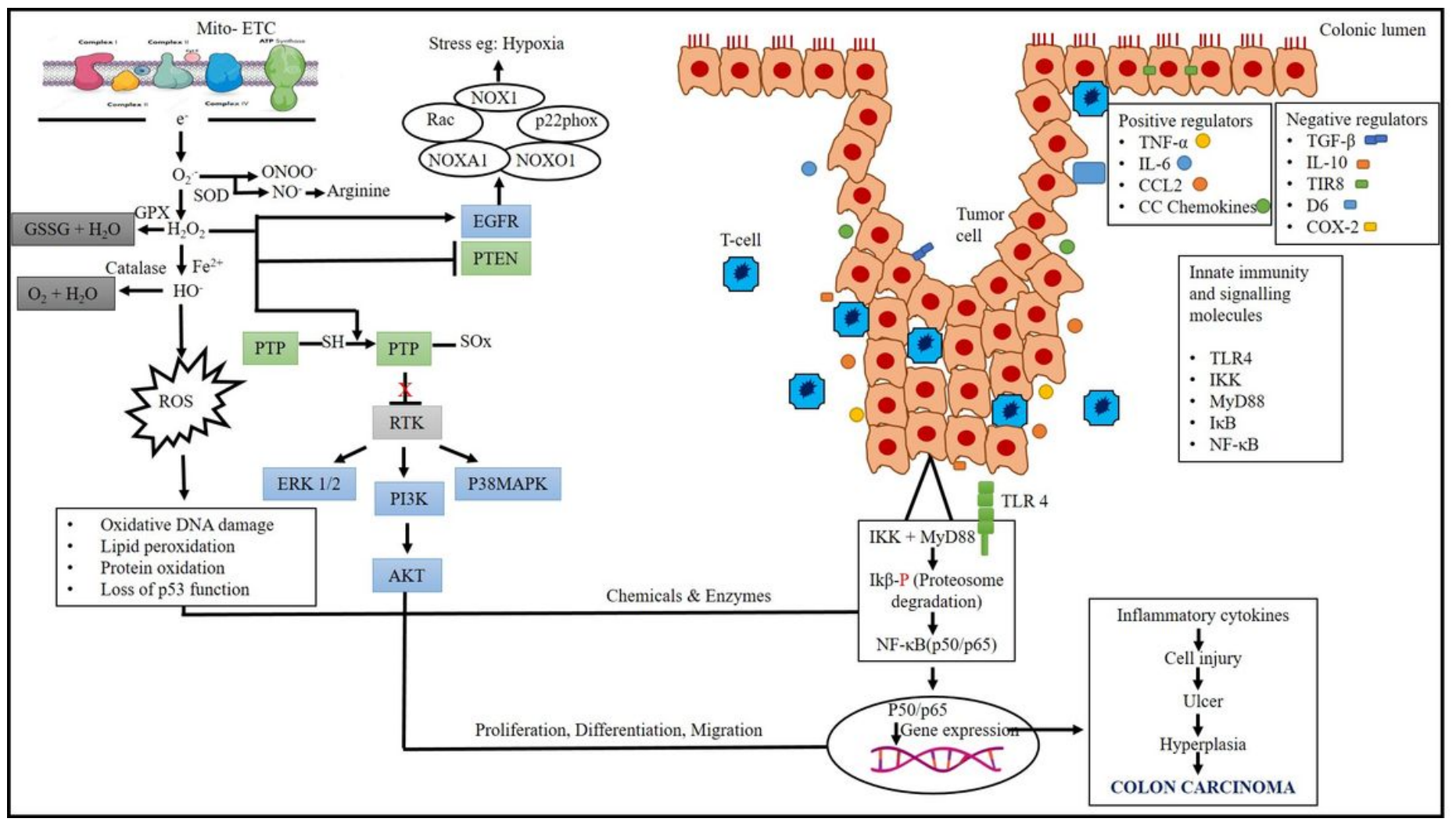

Figure 3

Colorectal cancer initiation \& progression by inflammation and oxidative stress. Colon cancer is caused excessive ROS production and inflammation leading to abnormal cell proliferation. ROS $(\mathrm{O} 2 ., \mathrm{H} 2 \mathrm{O} 2, \mathrm{OH}$.) is excessively generated from mitochondria leading to oxidation in DNA and protein, peroxidation in lipids and loss of p53 function. $\mathrm{H} 2 \mathrm{O} 2$ inhibits phosphatase and tensin homolog gene (PTEN). It also activates protein tyrosine phosphatase (PTP) which main role is to inhibit transmembrane protein receptor (RTK). $\mathrm{H} 2 \mathrm{O} 2$ will inhibit the role of PTP and activates Ras-dependent ERK 1/2, Phosphatidylinositol 3-kinase (PI3K) and p38 mitogen-activated protein kinases (P38MAPK) inducing Ak stain transforming (AKT) causing excessive proliferation, differentiation and movement of CRC. It also induces epidermal growth factor (EGFR), in turn activates NADPH oxidase organizer 1 (NOXO1), NADPH oxidase activator 1 (NOX01), human neutrophil cytochrome b light chain (p22phox), NADPH oxidase 1 (NOX1), Ras-related C3 botulinum toxin substrate (Rac) causing hypoxia condition in colon cancer patients. In the lumen, both the positive and negative regulators along with innate immune system and signalling molecules activates IKK with MyD88. This will induce IK $\beta$ which on phosphorylation degrades proteins and activates NF-KB. All the pathways meet in phosphorylation of NF-KB (p50/p65) which produces inflammatory cytokines that making cell injured and causing ulcer that leads to a condition called hyperplasia eventually leading to cancer. 


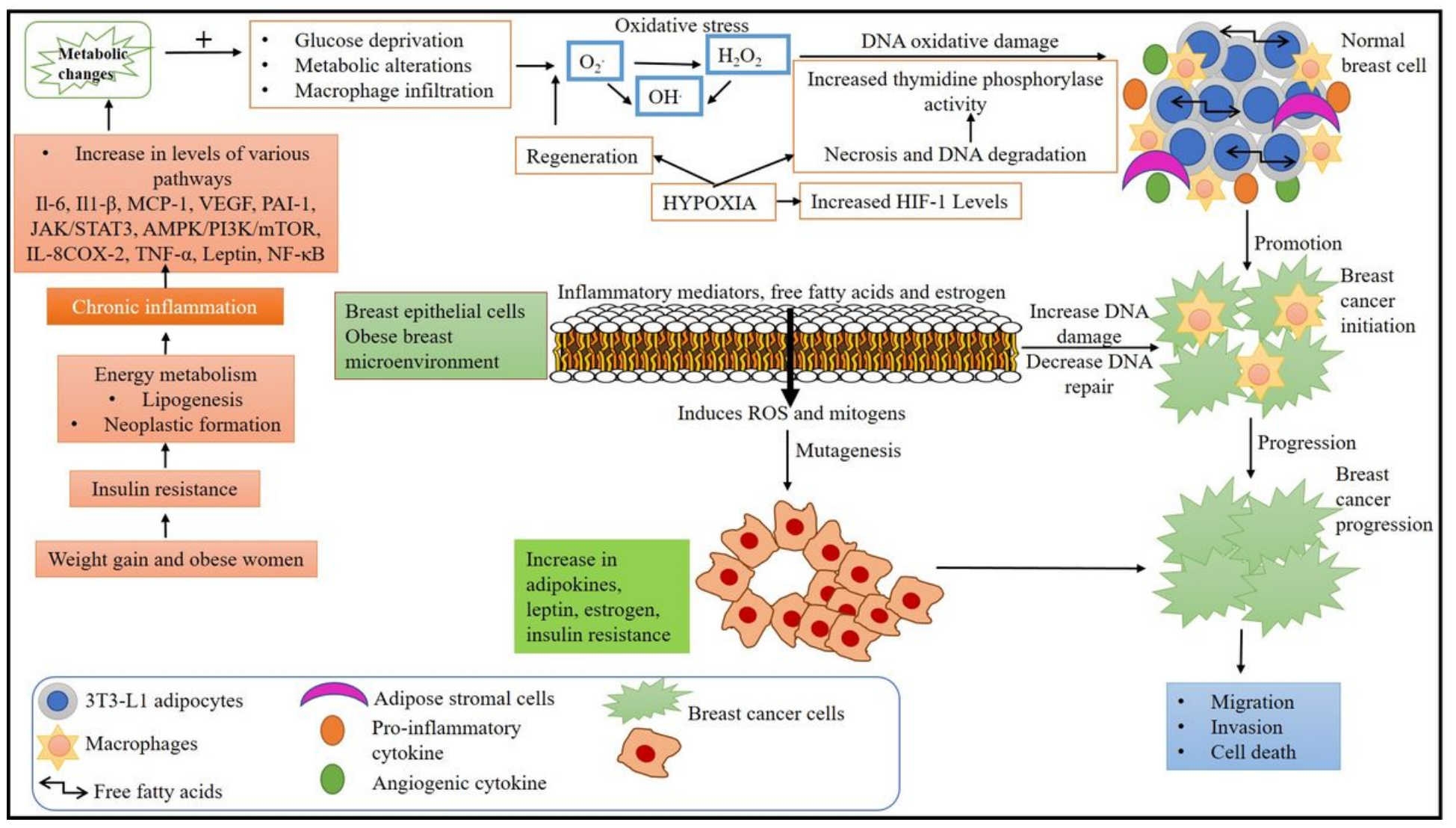

\section{Figure 4}

Breast cancer initiation \& progression by inflammation and oxidative stress. In obese women, weight gain roots to the progression of insulin resistance thereby causing chronic inflammation and increases other pathway levels (IL-6, TNF-a, Leptin, NF-KB, IL-8, COX-2, AMPK/PI3K, VEGF etc.) linking metabolic changes in the body. These changes along with glucose deprivation and macrophage infiltrations generates OS leading to DNA impairment in normal breast cells where increased HIF-1 levels are observed due to hypoxic stress. Hypoxia also increases necrosis and degradation in DNA increasing the activity of thymidine phosphorylase in normal cells. All these changes promote the initiation of BC. In breast epithelial cells, inflammatory mediators, free fatty acids and estrogen increases DNA damage and decreases DNA repair that promotes breast cancer. Also, these inflammatory mediators induce ROS and mitogens that increases adipokines, leptin, estrogen levels and insulin resistance. Inflammatory mediators along with ROS aids in the progression of BC causing intrusion and cell death. 


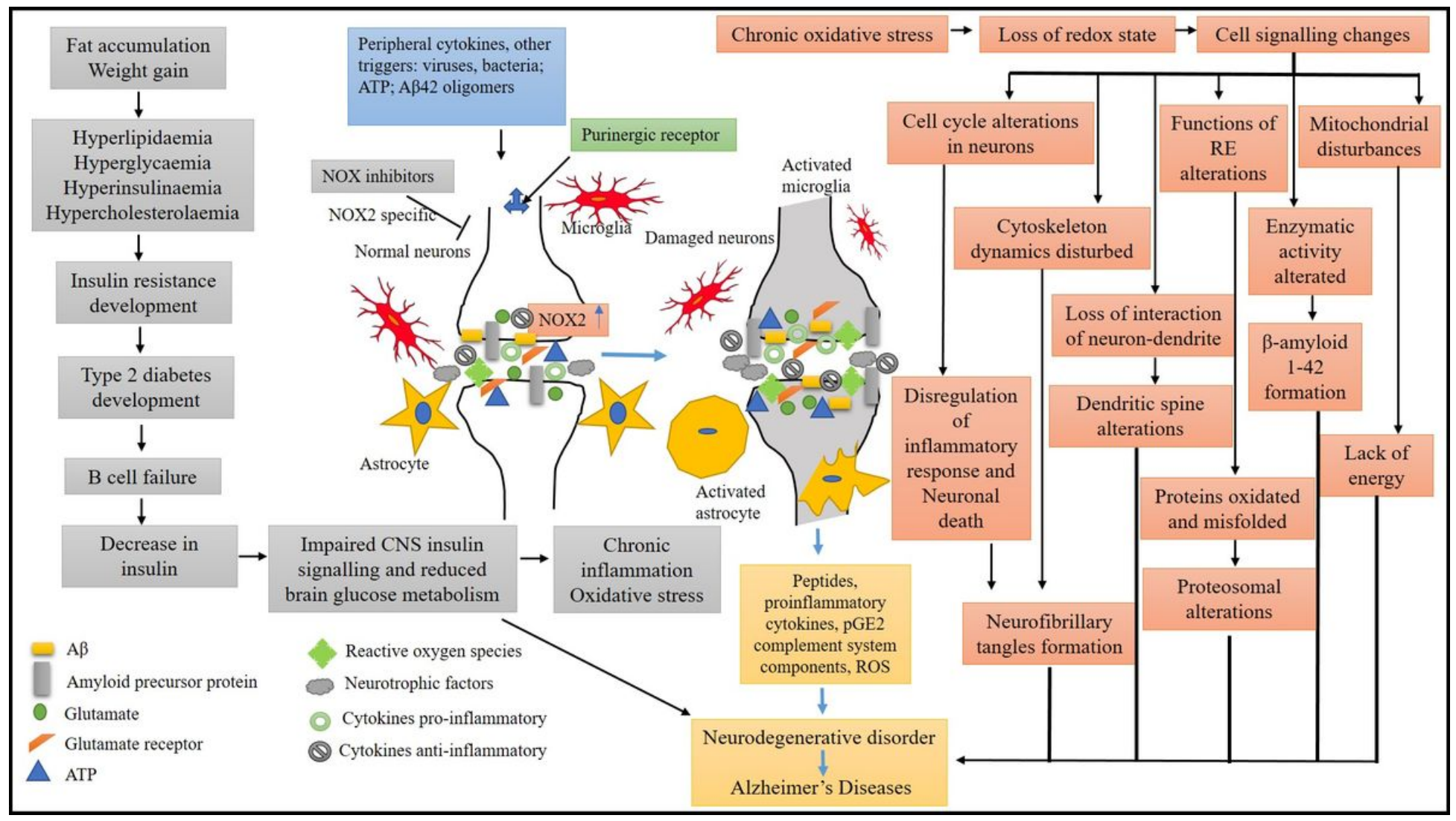

Figure 5

Lung cancer initiation \& progression by inflammation and oxidative stress. Exposure to cigarette smoke, particulate matter, carcinogenic metals, ionizing radiations, silica dusts, diesel fumes, dioxins, polychlorinated compounds cause oxidative stress. Oxidative stress increases lipid peroxidation (LPO), ROS and decreases sodium dismutase (SOD), glutathione (GSH). It activates NF-KB and causes damage to DNA. DNA damage increases the production of matrix metalloproteins (MMPs), ROS, chemokines and cytokines that induces inflammation, tissue injury and apoptosis. It brings to a condition of chronic obstructive pulmonary disease (COPD). COPD inactivates tumor suppressor genes, evades apoptosis, causes mutations and brings epigenetic modifications. All these conditions enhance cell proliferation, metastasis and angiogenesis eventually causing lung cancer. 


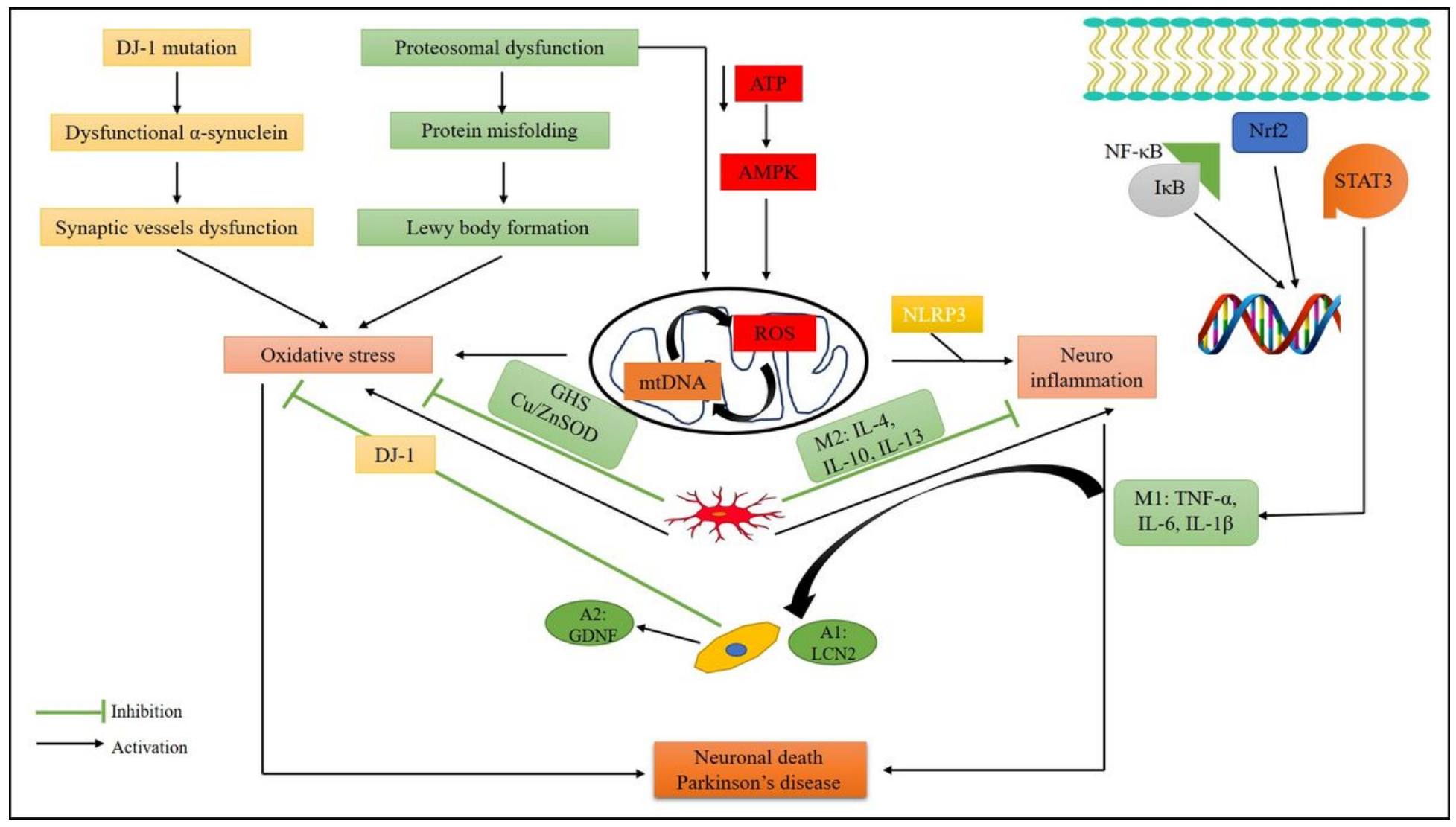

\section{Figure 6}

Alzheimer's disease initiation \& progression by inflammation and oxidative stress. Fat accumulation, weight gain, viruses, bacteria, ATP, AB42 oligomers, inflammation and chronic OS has an important part in Alzheimer's disease progression. First, accumulation of fat gains weight causing resistance in insulin level and developing T2DM. This causes failure in B cell thereby decreases in insulin production reducing glucose metabolism in brain. Decrease in metabolism increases chronic inflammation and oxidative stress. Second, peripheral cytokines, ATP, viruses, bacteria, Aß42 oligomers increases NOX2 in normal neurons and activates microglia and astrocyte that damages neurons. Damaged neurons contain higher levels of pro-inflammatory, anti-inflammatory cytokines, neurotrophic factors, ROS, ATP, glutamate, its receptors, $A \beta$ which increases inflammation and ROS in neurons. Third, due to chronic OS results in loss of redox environment brings cell signalling changes. These changes alter cell cycle causing dysregulation in inflammatory response and neuronal death, alters enzymatic activity leads to the formation of $\beta$ amyloid 1-42, disturbances in cytoskeleton dynamics causing neurofibrillary tangles, mitochondrial dysfunction leads to energy loss, alteration in RE functions leading to protein oxidation and misfolding and loss in neuron-dendrite interaction eventually leading to AD. 
Eg: cigarette smoke, particulate matter, carcinogenic metals ( $\mathrm{Cd}, \mathrm{Ni}, \mathrm{As}, \mathrm{Cr})$, ionizing radiations, silica dusts, diesel fumes, dioxins, polychlorinated compounds

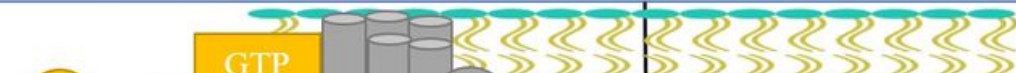

$\mathrm{RACl}$
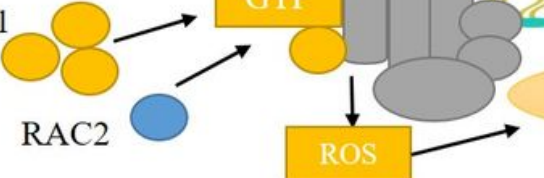

Oxidative stress (increase in ROS, LPO

Macrophages \&

Neutrophils activation

and decrease in SOD, GSH

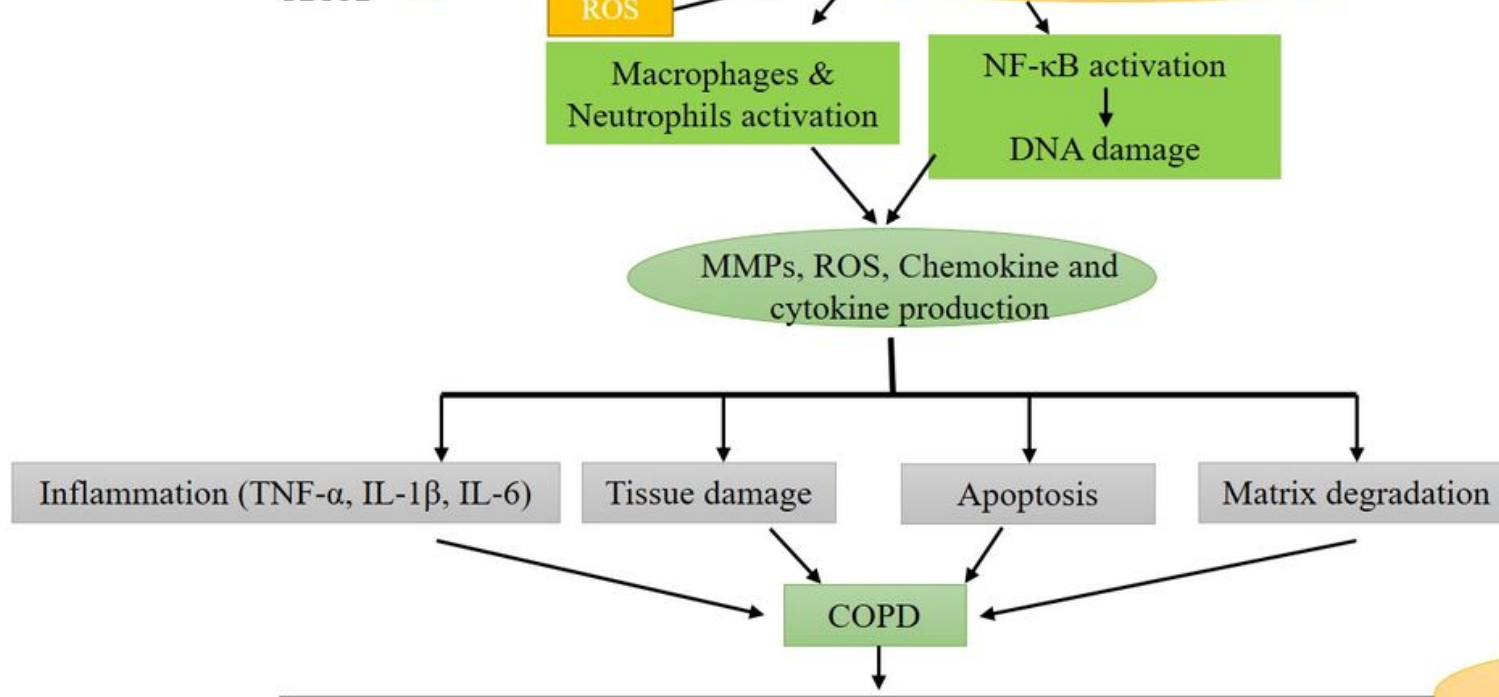

Epigenetic modifications, mutations, Evading apoptosis, Inactivation of tumor

Carcinogenesis

suppressor genes

Cell proliferation, metastasis,

angiogenesis

Lung cancer

Figure 7

Parkinson's disease initiation \& progression by inflammation and oxidative stress. OS is caused by mutation in DJ-1 and proteosomal dysfunction. It brings synaptic vessel dysfunction and lewy body formation respectively causing OS. Prolonged expose to ROS leads to mtDNA alterations enhancing oxidative stress. Also, dysfunction in mitochondria triggers the innate immune response activating the NLRP3 inflammasome complex through the production of cytokines. NF-KB, Nrf2 and STAT3 are the three crucial signalling pathway which has an important role in PD process. NF-kB combines with IkB, an inhibitory protein that enters the nucleus and mediates inflammation. Nrf2 is activated and entered the nucleus that also stimulates inflammatory response. Finally, STAT3 is stimulated and enhances the proinflammatory response of microglia. Microglia is the inflammation marker which is polarized to form M1/M2 phenotype having both pro- as well as anti-inflammatory effects. Microglia will not only induce oxidative stress but will also inhibit oxidative stress through activating GSH and Cu/ZnSOD. Additionally, astrocyte overexpressed DJ-1 exerts antioxidative stress which induced A1 astrocytes to polarize to A2 phenotype and produce GDNF which enhances neuron growth. Both OS and inflammation exerts their synergistic way in advancement of PD. 